\title{
CULTURA JURÍDICA Y LEGISLACIÓN CONTRA LADRONES ANTES DEL CÓDIGO PENAL DE 1837. UNA APROXIMACIÓN HISTÓRICA AL DERECHO PENAL REPUBLICANO TEMPRANO EN COLOMBIA (1820-1836)
}

Carlos Alberto Toro Silva*

Resumen: El presente artículo se aproxima al Derecho penal de transición entre el orden jurídico castellano-indiano del virreinato de la Nueva Granada y orden jurídico republicano, enfocándose en la legislación contra ladrones anterior al Código Penal de 1837. Esta legislación pretendía resolver el problema de los hurtos que había aumentado después de la Independencia. Inicialmente, durante la República de Colombia, predominó la dureza en los castigos, mientras que ya en la República de la Nueva Granada la legislación fue más moderada. Se muestra que la forma y estructura de estas leyes aún estaba influida por la cultura jurídica del virreinato, a pesar de los cambios en el discurso penal de las constituciones

* Abogado (2006), Universidad del Cauca (Popayán). Magíster en Historia, Universidad de los Andes. Doctor en Historia (2020), Universidad de los Andes. Bogotá, Colombia. Correo-e: ca.toro964@ uniandes.edu.co. Fecha de recepción: 18 de agosto de 2020. Fecha de aceptación: 12 de enero de 2021. Para citar el artículo: CARlos Alberto Toro Silva. "Cultura jurídica y legislación contra ladrones antes del Código Penal de 1837. Una aproximación histórica al derecho penal republicano temprano en Colombia (1820-1836)", Revista Derecho Penal y Criminología, vol. 41, n. ${ }^{\circ} 111$, julio-diciembre de 2020, Bogotá, Universidad Externado de Colombia, pp. 257-302. DOI: https://doi.org/10.18601/ 01210483.v41n111.08. 
de 1821 y 1832, de índole ilustrado-liberal. Al mismo tiempo que dicha legislación pretendía resolver un problema concreto, continuaron los debates sobre el Código Penal que, en 1837, daría inicio al Derecho codificado nacional. Esta política penal temprana también buscó mejorar los establecimientos de castigo, aunque sin éxito. Así, el Estado en ciernes aun estaba lejos de establecer un verdadero sistema penal. Para la investigación se usaron fuentes diversas buscando entender la legislación dentro de su contexto político e ideológico.

Palabras clave: cultura jurídica; ley; Código Penal; hurtos; política penal; historia del Derecho.

\title{
LEGAL CULTURE AND LEGISLATION AGAINST THIEVES BEFORE THE PENAL CODE OF 1837. A HISTORICAL APPROACH TO EARLY REPUBLICAN CRIMINAL LAW IN COLOMBIA (1820-1836)
}

\begin{abstract}
This article approaches the transitional criminal law between the Castilian-Indian legal order of the viceroyalty of New Granada and the republican legal order, focusing on the legislation against thieves prior to the Penal Code of 1837. This legislation intended to solve the problem of thefts that had increased after Independence. Initially, during the Republic of Colombia, harsh punishment prevailed, while in the Republic of New Granada the legislation was more moderate. It is shown that the form and structure of these laws was still influenced by the legal culture of the viceroyalty, despite the changes in the penal discourse of the 1821 and 1832 constitutions, of an enlightened-liberal nature. At the same time that said legislation sought to solve a specific problem, debates continued on the Penal Code which, in 1837, would give rise to the national codified law. This early penal policy also sought to improve punishment establishments, although without success. Thus, the fledgling state was still far from establishing a true penal system. For the research, various sources were used seeking to understand the legislation within its political and ideological context.
\end{abstract}

Keywords: legal culture; law; Penal Code; thefts; penal policy; history of law.

\section{INTRODUCCIÓN}

La historiografía jurídica nacional ha señalado, con razón, al Código Penal de 1837 como el punto de partida del Derecho penal en Colombia ${ }^{1}$. Ahora bien: como veremos,

1 Además de los manuales de Derecho penal que lo afirman, entre otros: Peñas Felizzola, Aura Helena. Génesis del sistema penal colombiano: utilitarismo y tradicionalismo en el código penal 
entre 1820 y ese código existió un derecho penal republicano referido a algunos delitos como los hurtos. Se trataba de una legislación de emergencia que no rompía con la cultura jurídica castellano-indiana vigente en el virreinato, cuando aún no existía un Derecho penal codificado sino disperso en diversas recopilaciones, cédulas reales y otras disposiciones, y cuando no existía una diferenciación entre leyes sustantivas y procesales. Así, el estudio de estas primeras leyes penales republicanas permite establecer una continuidad histórico-legal entre el Derecho castellano-indiano de la Colonia y el Derecho republicano codificado que comenzó a evolucionar a partir de 1837. En este artículo me enfoco en la legislación contra ladrones que, como veremos, no solo permite aproximarse al problema histórico de los alcances y límites del primer orden político republicano, sino que además nos da elementos sobre la cultura jurídica de transición de comienzos de la República, sobre la que aún sabemos poco.

De acuerdo con el historiador Germán Colmenares, el primer gran cambio entre la época colonial y el primer periodo republicano estuvo ante todo en el discurso ${ }^{2}$. A esto siguió una explosión de normas jurídicas con pretensiones de alcance nacional y sobre los más diversos asuntos. Este esfuerzo reformista a través de la ley no es simplemente una manifestación del "legalismo" santanderista ${ }^{3}$, pues, como muestra Harold Berman, ha sucedido después de todas las grandes revoluciones políticas de Occidente $^{4}$. El periodo que coincide con la República de Colombia (1819-1830) y el segundo gobierno de Santander ya en la República de la Nueva Granada (18321837) se caracterizó, pues, por la expedición de leyes y decretos no necesariamente coherentes entre sí, y frecuentemente modificados o reemplazados. Algunas de estas normas se referían a asuntos penales, como las que veremos en este artículo.

neogranadino de 1837, Bogotá, Doctrina y Ley, 2006, y "Utilitarismo y tradicionalismo en la legislación penal republicana: el código de 1837”, Revista Colombiana de Sociología, n. 26, pp. 9-42; Escobar Villegas, Juan Camilo y Maya Salazar, Adolfo León. "Los procesos de codificación penal en Nueva Granada: una ruta para la mundialización de las ideas ilustradas", Nuevo Mundo Mundos Nuevos (mai 2007), en http://journals.openedition.org/nuevomundo/3960; Parada García, Gilberto Enrique. "La retórica del miedo en la prensa bogotana de 1834". Historia Crítica n. . 36, jul.-dic., 2008, pp. 58-81, y “Orden y revolución en la ley penal colombiana (1819-1837). Un debate historiográfico". Anuario Colombiano de Historia Social y de la Cultura, vol. 36, n. 2, 2009, pp. 177-20, y Ley formal y ley material. La ley penal y su codificación en la construcción del Estado colombiano, 1819-1837. Ibagué, Universidad del Tolima, 2014. Por su parte, Salazar-Cáceres, Carlos Gabriel se limita a mencionar algunas de las leyes anteriores al Código de 1837 sin vincularlas a un contexto político y a la cultura jurídica de comienzos del siglo XIX, que es lo que pretendo hacer aquí. "Breve historia del Derecho penal colombiano”, Revista Principia Iuris, vol. 13 n. ${ }^{\circ}$ 26, pp. 35-53.

2 Colmenares, Germán. "El manejo ideológico de la ley penal en un periodo de transición”. En Colmenares, Germán. Varia. Selección de textos. Bogotá, Tercer Mundo Editores, Universidad del Valle, Banco de la República, Colciencias, 1998,pp. 258 y 259 [232-264].

3 Como argumenta Valencia Villa, Hernando. Cartas de batalla. Una crítica al constitucionalismo colombiano. Bogotá, Panamericana, 2010 [1987], pp. 118-124.

4 Berman, Harold, Law and Revolution. The Formation of the Western Legal Tradition. Cambridge y Londres, Harvard University Press, 1983, p. 29. 
Como veremos, las diferencias entre los gobiernos se reflejaron en la legislación contra ladrones: durante la República de Colombia, de mayor influencia militar, prevaleció una tendencia represiva en las leyes, con castigos duros que llegaban a la pena de muerte. Por el contrario, en la República de la Nueva Granada el gobierno buscó castigos más moderados que coincidían con la nueva orientación civilista de Santander. Estas leyes, como también mostraré, incluían aspectos sustantivos y procesales, lo que refleja las características de la cultura jurídica de un momento histórico de transición del Derecho castellano-indiano de índole casuista al Derecho republicano codificado. Este es el tema de las tres primeras secciones del presente artículo: la primera tratará sobre las percepciones gubernamentales sobre el delito; la segunda, sobre la cultura jurídica vigente a comienzos de la república, y la tercera sobre leyes del 17 de julio de 1820 , el 14 de octubre de 1821, el 3 de mayo de 1826 y el 6 de abril de 1836, cuyo contenido reflejaba lo primero (el interés gubernamental por encontrar una solución a los hurtos), y cuya forma y estructura se entienden dentro de dicha cultura jurídica, como veremos. La sección cuarta se referirá al contenido penal de las constituciones de 1821 y 1836, lo que permite ver el contraste entre el discurso político-programático garantista de ambos textos con la legislación anterior.

Además de esas leyes especiales, el proyecto de un nuevo código penal también forma parte de la política penal republicana contra la delincuencia en general, y los hurtos en particular, puesto que en él entrarían a definirse todos los delitos y sus correspondientes castigos. A diferencia de esas leyes, debido a lo notorio de su novedad, el Código Penal de 1837 ha suscitado un mayor interés en los investigadores, quienes han tendido a enfocarse más en el proceso de su formación e influencias ideológicas que en sus implicaciones en la administración de justicia ${ }^{5}$. El Código de 1837 daría inicio, en el caso colombiano, a la era del Derecho penal codificado, de una progresiva racionalización formal del Derecho y de predominio del principio de legalidad. Ese código y los subsiguientes fueron "expresión del principal límite de la arbitrariedad del poder a la vez que fundamentado del mismo: el principio de legalidad"6, marcando así una ruptura definitiva, al menos en el terreno del discurso estatal, con la cultura jurídica de Antiguo Régimen basada en el origen divino del poder político y de la concepción de este como jurisdicción ${ }^{7}$. A estas discusiones tempranas sobre el

5 Por ejemplo, las obras citadas al comienzo. Entre los que se refieren al contexto del primer Código está Gilberto Parada, quien identifica el "miedo" de la "élite” bogotana a la plebe como justificación discursiva para implementación de esta norma. Parada García, Gilberto Enrique, ob. cit. (2008). Como veremos, esa explicación es insuficiente.

6 Anitua, Gabriel Ignacio. "Contradicciones y dificultades de las teorías del castigo en el pensamiento de la ilustración”. En Rivera Bieras, Iñaki (coord.). Mitologías y discursos sobre el castigo. Historias del presente y posibles escenarios. Barcelona, Anthropos, 2004, p. 17.

7 Lo que era la regla durante el periodo colonial: todo empleo público, de la naturaleza que fuera, implicaba un grado mayor o menor de jurisdicción. La separación entre poderes públicos era, por tanto, una novedad radical a comienzos de la república. 
Código, que contrastan con la legislación mencionada en las tres primeras secciones, me referiré en cuarto lugar.

Finalmente me referiré a las normas sobre presidios, otro problema que el gobierno buscó solucionar de su interés por afianzar su poder coactivo y la creciente delincuencia patrimonial, aunque sin éxito. La falta de presidios y su inseguridad para contener a los reos, características que venían del periodo colonial, era también una preocupación constante entre los gobernantes colombianos y neogranadinos. Como puede ver el lector, el artículo se enfoca en el estudio de la legislación en su contexto político e ideológico -la "cultura jurídica de transición" que he mencionado-. Las implicaciones procesales de las leyes contra ladrones, especialmente la del 3 de mayo de 1826, serán materia de otros textos.

Finalmente, como también podrá notar el lector, el método de este trabajo es estrictamente histórico. En primer lugar, adopta el punto de vista de vista de un observador, dirigido desde el exterior hacia el Derecho ${ }^{8}$. Esto implica evitar una evaluación del Derecho del pasado desde los criterios internos del sistema jurídico del presente. Por eso, en segundo lugar, el artículo sigue el criterio de que el historiador debe estar atento tanto al contexto como a las influencias del pasado sobre el pasado que a su vez está estudiando, si no quiere distorsionar la realidad histórico-jurídica que le interesa comprender al desvincularla de sus propias continuidades. En cuanto a las fuentes utilizadas, teniendo en cuenta las características de la investigación, que, insisto, busca vincular la legislación a una política penal y a una cultura jurídica histórica, el estudio se basó en fuentes diversas además de la legislación. Utilicé los informes gubernamentales en los que se mencionaban aspectos de la política penal, algunos documentos del Archivo General de la Nación (en adelante, AGN) referidos a las implicaciones de esta nueva legislación y algunos textos de la prensa de la época, entre otras fuentes.

\section{LAS PERCEPCIONES GUBERNAMENTALES SOBRE LOS HURTOS COMO PROBLEMA SOCIAL A COMIENZOS DE LA REPÚBLICA}

El problema público de los hurtos, que había sido motivo de preocupación de las autoridades durante el virreinato, recobró importancia después de la Independencia. Antes de eso, con la primera ruptura de 1810, en debates como la constituyente de Cundinamarca de 1811 , por ejemplo, hubo pocas referencias concretas ese problema, lo que debía ser consecuencia de las urgencias del periodo. Luego de la Independencia reaparecería la preocupación gubernamental por la delincuencia común en algunas regiones de la nueva república, particularmente en la capital ${ }^{9}$.

8 Criterio básico señalado, por ejemplo, por Stolleis, Michael en su obra Introducción al Derecho público alemán (siglos XVI-XXI). Madrid, Marcial Pons, 2017, p. 33.

9 Sobre esta preocupación y los cambios en la administración de justicia y la delincuencia en ente el virreinato y la República temprana, mi propia tesis doctoral ya mencionada. 
El control de la delincuencia fue una preocupación constante para el gobierno durante la República de Colombia (1819-1830), que al mismo tiempo buscaba imponer un Poder Ejecutivo fuerte y estable ${ }^{10}$. Así, la administración de Francisco de Paula Santander (1819-1827) sancionó algunas leyes que endurecían los castigos por delitos contra la propiedad como consecuencia de su aumento después de las guerras de Independencia. En este periodo, el incipiente Poder Ejecutivo estaba encabezado por oficiales del ejército libertador en el nivel central, mientras que en los cantones era ejercido por los jueces políticos ${ }^{11}$. Durante la administración de Simón Bolívar (1827-1830) el control de la delincuencia siguió siendo una preocupación gubernamental. Por ejemplo, para responder a las diversas quejas de los ciudadanos relativas a la frecuencia de los hurtos, el Ejecutivo fue autorizado para nombrar jefes de policía en Bogotá y otras capitales, poniéndolos bajo la dependencia de los intendentes ${ }^{12}$. La parte final de la República de Colombia (1830) se caracterizó por sus conmociones políticas: la separación efectiva de Venezuela, que había convocado a un congreso constituyente e impedido el paso a la comisión de paz que el propio Congreso había enviado a dialogar; la aparente agregación de la provincia de Casanare a Venezuela, y la amenaza de separación del Departamento del Sur. En estas críticas circunstancias el Estado en ciernes difícilmente podía asegurar la seguridad de todo el territorio ${ }^{13}$.

Más adelante, los creadores de la nueva República de la Nueva Granada, luego de la rebelión de Rafael Urdaneta, "se comprometieron a reintegrar la Nueva Granada contra otros proyectos políticos que amenazaron con fragmentar la antigua unidad jurisdiccional neogranadina" 14 . Los conflictos entre las fuerzas llaneras y el gobierno de la recién creada república motivaron también que el gobierno buscara reducir la influencia militar. El segundo gobierno de Santander (1832-1837), liberal y autoritario al mismo tiempo, buscaba un Estado central fuerte guiado por las leyes ${ }^{15}$.

El problema del control de la delincuencia era planteado desde el gobierno, dentro de un discurso coherente con los criterios con los que los nuevos dirigentes pretendían regir la sociedad republicana, como los derechos individuales, dentro de los que se encontraba el de propiedad ${ }^{16}$. De todos modos, en la práctica lo que los gobernantes y jueces seguían buscando proteger a través de la administración de justicia criminal

10 Martínez Garnica, Armando. La Agenda de Colombia, t. I. Bucaramanga, Universidad Industrial de Santander, 2008, pp. 167 y 199.

11 Ibíd., p. 141.

12 Ibíd., t. II, p. 99.

13 Ibíd., p. 125.

14 Ibíd., p. 222.

15 Lynch, John. "La formación de los Estados nuevos”. En Manuel Lucena Salmoral (coord.). Historia de Iberoamérica, t. III. Madrid, Cátedra, 2008, p. 206 [131-247].

16 Según el artículo 3 de la Constitución de 1821, era "un deber de la nación proteger por leyes sabias y equitativas la libertad, la seguridad, la propiedad y la igualdad de todos los colombianos". 
ordinaria era el orden social en general, más que los derechos del afectado individualmente considerado. En este sentido hubo una continuidad con los criterios de las autoridades del virreinato de la Nueva Granada, entre las que prevalecía criterio de utilidad pública para perseguir y castigar a los delincuentes. El aspecto individual del daño causado por los delincuentes era secundario.

La década de 1820 se caracterizó por el aumento de la población de antiguos combatientes en Bogotá y por el incremento de los hurtos en la ciudad y sus alrededores. Estanislao Vergara afirmaba en 1820, por ejemplo, que los derechos de propiedad y de seguridad estaban siendo atacados por "algunos malvados" que escalaban las casas, violentaban y maltrataban a los dueños y les pillaban sus bienes, y que hasta en Santa Fe y sus arrabales se sufría ese mal, a pesar de la vigilancia de los magistrados y del celo de las patrullas ${ }^{17}$. Asimismo, en los debates constitucionales de Cúcuta de 1821, los hurtos aparecían mencionados como una transgresión al orden público originada a su vez en el desorden posterior a la guerra, lo que quedó señalado en la ley contra ladrones de ese año. Esta norma fue un resultado de la solicitud del gobernador de Casanare para que se le permitiera imponer penas capitales luego de un corto sumario a los cuatreros y bandidos que se habían levantado en aquella provincia, por ser este, a su juicio, el medio "más seguro para extirpar aquella clase de malhechores que con motivo de la guerra se ha aumentado en dicha provincia" 18 .

En 1827, el propio José Manuel Restrepo atribuía la multiplicación de los ladrones en algunos puntos de la República a motivos exclusivamente relacionados con limitaciones en las leyes, el juicio y el castigo. Así, en su opinión, el problema se debía a las dificultades que retardaban la conclusión de los procesos y que facilitaban a los reos eludir las penas. A su juicio,

una parte de los defectos que se notan puede originarse en las leyes españolas que todavía son la base de nuestra legislación criminal, a la poca seguridad de las cárceles, al descuido a veces punible de los jueces de primera instancia para aprehender a los reos e imponerles el condigno castigo y a la falta de presidios o lugares en que se cumplan las penas ${ }^{19}$.

Concluía que, a pesar de todas las reformas introducidas por las leyes contra ladrones de 1826, el mal continuaba aun después de haberse aplicado la pena de último

17 Vergara, Estanislao. "Memoria del encargado del Despacho del Interior y Justicia del Departamento de Cundinamarca, presentada a su excelencia el Vicepresidente el 31 de diciembre". En Gómez Rodríguez, Luis Horacio (comp.). Administraciones de Santander, t. I. Bogotá, Fundación Francisco de Paula Santander, 1990, p. 31.

18 “Sesión del día 12 de julio de 1821 ", 237.

19 Restrepo, José Manuel, "Exposición que el secretario de Estado del despacho del interior del gobierno de la República de Colombia hace al Congreso de 1827 sobre los negocios de su departamento", en Gómez Rodríguez, Luis Horacio (comp.), ob. cit., p. 264. 
suplicio en algunos casos, y que era posible que dicha ley no se hubiera ejecutado con el debido rigor por los jueces que debían imponer el castigo ${ }^{20}$. El texto de Restrepo resulta de interés asimismo porque en él se menciona por primera vez en Colombia, de forma implícita, la idea de un sistema penal: una legislación criminal, una justicia encargada de ejecutar la ley y unas prisiones para cumplir las penas; solo le faltó referirse a un cuerpo de policía para completar una representación discursiva completa de un sistema penal. A comienzos del siglo XIX la policía, vale la pena señalar, seguía teniendo el mismo significado que durante el periodo colonial, es decir el orden y arreglo de la ciudad, aunque en ocasiones ya comenzara a ser asociada a un cuerpo o institución con funciones específicas de mantenimiento del orden público ${ }^{21}$. Más adelante, en 1838, Lino de Pombo ya afirmaba que la causa del aumento de los hurtos debía buscarse en la falta de un sistema de policía eficaz y bien arreglado $^{22}$. La creación de un cuerpo de policía en Colombia solo tendría lugar mucho más tarde, y en el periodo republicano a que se refiere esta investigación no solo no existía un cuerpo de policía sino en general un sistema penal: no había una justicia penal con funciones específicas separada de la civil (los jueces ordinarios seguían encargados de ambos tipos de causas), ni un código, ni prisiones modernas.

Argumentos como los de Restrepo y medidas represivas como las leyes contra ladrones de 1821 y 1826 parecerían contradecir la imagen de tranquilidad en la República que el propio Restrepo y otros miembros del Gobierno presentaban al Congreso ${ }^{23}$. Sin embargo, esta aparente contradicción puede entenderse a la luz de lo planteado por Antonio Annino, en su texto sobre el primer liberalismo hispanoamericano, en el que señala que el imaginario social de muchos liberales era "sumamente moderado", mientras que su imaginario político era "jacobino", "en el sentido de teorizar la necesidad de poderes fuertes [...], no solo para ganar las batallas en contra de la iglesia o los grupos disidentes, sino también para construir la identidad nacional $a b$ origine" ${ }^{24}$. Así, aunque sus representaciones sobre la sociedad fueran moderadas, a la hora de buscar resolver problemas concretos la delincuencia en este primer periodo

20 Ibíd., p. 264.

21 "El poder ejecutivo piensa que produciría grandes ventajas al servicio público, aún bajo el aspecto económico, la creación de tres compañías de resguardo de policía, a las cuales estuviese encargado prestar mano fuerte a las autoridades del orden político para el desempeño de sus funciones, escoltar las conducciones de reos y de efectos nacionales, custodiar los presidios, y perseguir a los criminales o malhechores". Pombo, Lino de. "De los secretarios de estado en los despachos del interior y hacienda del gobierno de la Nueva Granada al congreso constitucional del año 1838”, en Gómez Rodríguez, Luis Horacio (comp.), ob. cit., t. vI, p. 204.

22 Ibíd., p. 203.

23 Que aparece en los informes de gobierno incluidos en Administraciones de Santander.

24 Annino, Antonio. "El paradigma y la disputa. Notas para una genealogía de la cuestión liberal en México y América Hispánica”. En Palti, Elías José (org.). Mito y realidad de la 'cultura política latinoamericana'. Debates en IberoIdeas. Buenos Aires, Prometeo Libros, 2010, p. 67 [45-67]. 
republicano, de gran influencia militar en el gobierno, prevalecía el interés por castigar con dureza a los delincuentes.

Esto se observa en las ideas de José Manuel Restrepo, quien en su Historia de la Revolución comenzaba refiriéndose al gobierno y la justicia coloniales como despóticos y hablaba en términos muy moderados de sus compatriotas americanos, incluyendo las castas ${ }^{25}$, mientras por otro lado defendía una represión más dura de los delitos. Se trataba, pues, de contribuir a una autorrepresentación en términos favorables de la nación en ciernes (además, como aparece en los informes, de mostrar un gobierno efectivo), pero al mismo tiempo de afirmar la capacidad de la naciente organización política no solo para crear su propio orden social sino además para mantenerlo. El imaginario social moderado y el discurso penal garantista constituían una "pareja" en el lenguaje gubernamental que entraba en tensión con la necesidad que desde el gobierno y los jueces se expresaba sobre la necesidad de un castigo pronto, ejemplar y expedito a quienes cometieran delitos contra la propiedad que se habían convertido en una preocupación constante en el periodo.

Los hurtos y robos no solo eran un problema de las zonas más conflictivas de la nación en ciernes, sino que de hecho las autoridades los veían como los delitos más comunes y, en ese sentido, un problema sensible. Estanislao Vergara se lamentaba en 1820 de los robos en Santa Fe, y Restrepo en 1827 mostraba su preocupación por la multiplicación de los ladrones que había motivado la ley contra ellos. Ese mismo año, la Corte Suprema, en un informe al Ejecutivo sobre el cumplimiento de dicha ley, señalaba que había sido sancionada "en las circunstancias de verse plagada esta ciudad, y sus cercanías de ladrones", "que asaltaban con mano armada la vida, y propiedades de los ciudadanos" 26 . Para la Corte, el hurto era el delito "que más comúnmente se comete y aflige a los ciudadanos pacíficos" 27 y "los robos, los asesinatos y otros atentados se [estaban] haciendo frecuentes en algunas partes de la República" 28 . Estas afirmaciones muestran que los hurtos y robos crecientes eran un motivo de alarma para las autoridades a pesar de su imaginario social moderado.

25 "Así las calidades de los criollos, blancos y pardos de la Nueva Granada y Venezuela bajo un buen gobierno, en que no reinara la inquisición y el despotismo como en el sistema colonial, eran capaces de formar un pueblo nuevo en poco tiempo, y de producir grandes hombres en todos los ramos". Restrepo, José Manuel. Historia de la Revolución, t. I. París, Librería Americana, 1827, p. 105.

26 "Informe que ha dado la Corte Superior de Justicia de estos Departamentos al Supremo Poder Ejecutivo sobre la reforma de las leyes orgánicas de procedimiento civil, y contra los ladrones, a consecuencia del anónimo inserto en el Conductor n. 27”, AGN, Sección República, Juzgados y Tribunales, tomo 22, p. 8.

27 AGN, Sección República, Juzgados y Tribunales, tomo 22, f. 321r.

28 "Observaciones que la alta Corte de Justicia, con motivo de la excitación hecha por el Poder Ejecutivo en nota del 3 de nov. del año anterior hace acerca de algunas imperfecciones o vacíos, que en su concepto son más notables en el presente estado de la legislación, relativo a la administración judicial", AGN, Sección República, Juzgados y Tribunales, tomo 20, ff. 430 r. y v. 
También puede notarse que el periodo en que esta preocupación por los hurtos apareció con mayor fuerza era el comprendido entre 1819 y $1830^{29}$. De todos modos, la imagen general de la buena índole del pueblo neogranadino siguió predominando en el discurso gubernamental y público. En 1832, por ejemplo, apareció este tex to en la Gaceta de la Nueva Granada que es representativo de la imagen que los nuevos sectores dirigentes buscaban difundir sobre la sociedad y el pueblo de la nación en ciernes:

Algunas veces hemos oído tachar a nuestro pueblo de inmoral y grosero, por algunas faltas que ha solido cometer en las funciones públicas. Inculto y bárbaro lo han apellidado algunos; pero nosotros podemos asegurar que él es de los más morigerados y urbanos de la tierra. Cuando con motivo de algún disgusto particular, se ha formado algún tumulto en que un crecido número de ciudadanos ha tomado parte, siempre los hemos visto apaciguarse en el momento en que se ha oído la voz de la autoridad pública. Nunca se ha insultado, ni se ha arrojado todo a los magistrados, como puede verse en naciones que llevan la fama de mal civilizadas. Los correos transitan por los caminos públicos con sumas de cincuenta y sesenta mil pesos, sin que hayan sido robados. Entre nosotros no hay asonadas de que todos los días hablan los papeles extranjeros, y esto después de una guerra de veinte años, y de una serie de trastornos políticos que habrían sido capaces de introducir la mayor confusión y desorden en otro pueblo que no tuviese una índole tan buena como el nuestro ${ }^{30}$.

Y en 1836, durante las discusiones en el Congreso sobre el Código Penal, uno de los senadores argumentaba, al favorecer unas eventuales penas benignas en dicha norma, que

Toda nuestra legislación respira humanidad, acorde con las ideas del siglo, no pide víctimas, solo quiere escarmiento, y calculada para la sociedad granadina en donde son raros los grandes crímenes deben ser raros los grandes castigos. Nuestras costumbres nada tienen de feroz; la religión, la educación, el clima, la sensibilidad y todas las causas a que la especie humana debe su mejora concurren entre nosotros a disminuir los delitos, y solo es útil la severidad de las penas en una sociedad corrompida ${ }^{31}$.

Aunque este discurso favorable al pueblo fuera similar al de la década anterior, de todos modos, el contexto político era distinto, comenzando por la tendencia civilista

29 Aunque, como señala Gilberto Enrique Parada continuó entre las “élites” en la década siguiente. Parada García, Gilberto Enrique, pp. cit. (2008).

30 "Parte no oficial. Moral y urbanidad del pueblo". En Gaceta de la Nueva Granada n. 53,30 de septiembre 1832 .

31 "Sesión de la noche del 18 de marzo de 1836", en cámara del senado, Diario de debates de la honorable Cámara del Senado. Bogotá, Imp. por J. Ayarza, 1836., p. 125. 
del gobierno de Santander, diferente del predominio militar en el gobierno durante la República de Colombia. Esta imagen favorable contrasta con la percepción de inseguridad generalizada que, según Gilberto Parada, se había propagado entre la élite bogotana en el periodo anterior a la expedición del Código Penal de $1837^{[32]}$. Ahora bien, no es esta percepción, que refleja el aumento de los mendigos y ladrones en Bogotá, lo que motivó la redacción del código (cuya necesidad ya habían planteado los constituyentes de Cundinamarca de 1811), sino lo contrario: sus redactores estaban convencidos de estar creando un cuerpo legal a su juicio más "humano" que la legislación española anterior, y dirigido a un pueblo que consideraban de buena índole. Así, la representación favorable del pueblo servía para el fin político de crear un cuerpo normativo que rompiera con la legislación castellana vigente.

Los vagos y su relación con la delincuencia también fueron también una constante preocupación gubernamental en las décadas de 1820 y 1830. De hecho, la vagancia era un asunto que el gobierno virreinal también había tratado resolver mediante sanciones utilitarias, continuando con la tradición del Derecho castellano, sobre todo para evitar, en términos del virrey Ezpeleta, que "de vagos pasaran a delincuentes"33. Más adelante, la actitud de los representantes del Congreso de las Provincias Unidas de la Nueva Granada (1811) ante esta población era la castigarlos con el destierro, al determinar que los mendigos, vagos y prófugos de la justicia no tenían el derecho de los habitantes libres de las provincias a entrar en el territorio de las demás ${ }^{34}$. El destierro, una pena propia de un orden social compuesto por corporaciones (como las ciudades y la familia) más que por individuos, desaparecería como solución al problema de la vagancia en las décadas siguientes.

El vínculo entre vagancia y delincuencia apareció de nuevo en la ley contra ladrones del 3 de mayo de 1826. Esta iba encaminada, en principio, a endurecer las penas contra ciertos atentados contra la propiedad en la capital y a establecer un procedimiento más expedito para ese efecto, pero además incluyó una sección sobre los vagos, que según el artículo 30 deberían ser destinados al servicio de la marina.

En la década de 1830 la preocupación por la vagancia como origen del delito se hizo más visible en los discursos gubernamentales, enfatizando esta vez en la necesidad de la prevención del segundo a través de la represión de la primera. Así, para el secretario de Estado en 1836, Lino de Pombo, una sociedad bien organizada no podía permitir vagos en su seno, por ser "peste del Estado y el semillero de los vicios y

32 Parada García, Gilberto Enrique, ob. cit. (2008).

33 Ezpeleta, Josef de. "Relación del gobierno". En Colmenares, Germán (ed.). Relaciones e informes de los gobernantes de la Nueva Granada, t. II. Bogotá. Fondo de Promoción de la Cultura del Banco Popular, 1989, p. 207 [153-330].

34 “Acta de Federación”. En Posada, Fernando (comp.). Congreso de las provincias unidas 1811-1814, t. I. Bogotá, Fundación Francisco de Paula Santander, 1989, p. 14. 
de los crímenes". Asimismo, afirmaba que todo cuanto contribuyera "a vivificar la industria, a difundir las luces, a depurar las costumbres, a alentar el incremento de la población", tendería igualmente

hacia la extirpación de la vagancia, disminución de los mendigos, y prevención de los deslices juveniles que sirven de primeros ensayos, para los grandes crímenes; y los reglamentos locales de policía, cuando puedan expedirse, auxiliaran poderosamente en este sentido la benéfica influencia de las leyes ${ }^{35}$.

A su juicio, con el fin de prevenir antes que castigar los delitos, era necesario perseguir a los vagos y mal entretenidos y forzarlos con penas correccionales al trabajo que aumentara la riqueza pública y que impidiera que se convirtieran en una carga para el cuerpo social ${ }^{36}$. Insistía en la necesidad de casas de corrección para remediar los "perniciosos efectos de la vagancia, que aún se trasmite como herencia de padre a hijo, y convertir en miembros útiles de la sociedad a los que son hoy en día miembros engangrenados o lo serán más tarde" 37 . El vago, a juicio de Pombo, medraba "a costa ajena, y solo vivía para sí “olvidando hasta los más sagrados deberes naturales", y el origen de la vagancia estaba en los "vicios de la educación, por falta de estímulos o por natural indolencia" que hacían adquirir el "habito funesto de la ociosidad", y llevaba a la "depravación de las costumbres". En su opinión, eran necesarios todos los esfuerzos para extirpar la vagancia y la mendicidad y para rehabilitar en ella a multitud de individuos que en calidad de vagos y de mendigos la sirven ahora de molesta carga, serán otros tantos pasos importantes en favor de la moral, de la industria y de la riqueza nacional. Los verbos señalados indican el origen social del problema, y como tal posible de resolver ${ }^{38}$. Estas ideas, de nuevo, aparecen recogidas en la ley del 6 de abril de 1836.

\section{ORDEN, SEGURIDAD Y JUSTICIA EN LA CULTURA JURÍDICA DE COMIENZOS DE LA REPÚBLICA}

En esta sección me referiré a las concepciones sobre el orden y la seguridad en el periodo republicano temprano, al que me he referido como "de transición". A finales del siglo XVIII y comienzos del XIX el orden social seguía teniendo un origen divino en la Monarquía española y sus colonias. Con la crisis de 1808 inició un "desplazamiento semántico del concepto" alrededor de la idea de un orden "nuevo" en

35 Pombo, Lino de, "Informe del presidente Santander 1836", en Gómez Rodríguez, Luis Horacio (comp.), o. cit., t. IV, p. 38.

36 Soto, Francisco. "Exposición que el secretario del interior y relaciones exteriores del gobierno de la Nueva Granada, hace al congreso constitucional del año de 1833, sobre los negocios de su departamento", en Gómez Rodríguez, Luis Horacio (comp.), ob. cit., t. III, p. 129.

37 Pombo, Lino de, ob. cit., p. 16.

38 Ibíd., p. 217. 
contraposición al antiguo o anterior ${ }^{39}$. En el caso neogranadino, comenzó a cambiar "la manera como los neogranadinos se sitúan ante la cuestión de la constitución, esto es, ante la cuestión del orden" 40 . Hasta ese entonces, la Constitución se refería a las reglas escritas y no escritas de la monarquía corporativa; pero su significado comenzó a cambiar en el contexto de dicha crisis. En el contexto de formación de juntas locales derivado de la crisis monárquica de 1808 se intensificó el uso del término constitución, y asimismo creció la idea de que era preciso darse una, entendida ya no como la preservación del orden existente, sino como el fundamento de un orden nuevo. Así, a partir de 1811 las instancias gubernativas (cabildos y juntas) de las provincias de la Nueva Granada comenzaron a desarrollar su iniciativa de redactar y promulgar constituciones ${ }^{41}$. Una de las primeras fue precisamente la de la provincia de Cundinamarca en 1811, que a su vez fue reformada en 1812.

El periodo comprendido entre 1810 y 1819 se caracterizó por los conflictos internos derivados de las dificultades para establecer un orden político nuevo para el antiguo virreinato, de restauración por parte de los ejércitos de la Corona entre 1815 y 1819 , y de victoria de los ejércitos republicanos en ese año. Además de los cambios constitucionales en los términos jurídico-políticos de comprensión del orden social, este periodo de guerras y cambios acelerados terminó alterando profundamente el orden político y social del antiguo virreinato.

Por este motivo, después de la separación de 1819 el problema del mantenimiento del orden fue una preocupación central entre los gobernantes colombianos. Por ejemplo, en el nuevo orden social ya no había un monarca, quien había sido "el eslabón final de una cadena de fidelidades que daba consistencia a las órdenes, estados o jerarquías", cuya desaparición implicaba el riesgo de agitar la discordia "y dejar sin freno las pasiones de la plebe" 42 . La aspiración de los gobernantes era que el lugar antes ocupado por el "consenso religioso-moral y un sistema de fidelidades que daban forma orgánica a los órdenes sociales fuera ocupado por un culto abstracto a la ley”, que daba "forma y figura tangibles al espacio público"43.

La preocupación por el problema del orden se observa en que la noción adquirió connotaciones diversas como las de "orden público", "orden legal" y "orden

39 Leal Curiel, Carole. "El concepto de orden en Iberoamérica. El orden entre dos voluntades: divina y humana”. En Fernández Sebastián, Javier (ed.). Diccionario político y social del mundo iberoamericano. Conceptos políticos fundamentales, 1770-1870 t. II. Madrid, Centro de Estudios Políticos y Constitucionales, Universidad del País Vasco, 2014.

40 Vanegas, Isidro. "El constitucionalismo revolucionario en la Nueva Granada. Procesos n. ${ }^{\circ} 37$, Primer semestre 2013, p. 38 [35-56].

41 Vanegas, Isidro. Ibíd., pp. 38-44.

42 Colmenares, Germán. "La ley y el orden social. Fundamento profano y fundamento divino". En Colmenares, Germán, ob. cit., p. 226 [209-229].

43 Ibíd., p. 227. 
constitucional" 44 . Esto aparece en los informes de secretarios de Estado, en los que tiende a predominar el uso de la expresión "orden público", identificado en ocasiones con la "tranquilidad pública" 45 . Otros términos relacionados eran los de la paz interior, seguridad pública (que ya venía usándose por los fiscales en los juicios en el siglo anterior) y la seguridad individual desde la década de 1820. Este último término implicaba una novedad con respecto a la cultura jurídica del virreinato, en la que los intereses individuales estaban subordinados a los del grupo o cuerpo social.

De todos modos, a comienzos del periodo republicano, los gobernantes seguían asociando la gravedad del delito a su atentado contra el cuerpo social, lo que aparece, por ejemplo, en la Constitución de 1821. Esto parecería implicar que los delitos contra los derechos individuales como los hurtos serían de menor gravedad que los que atacaban ese "orden social". Sin embargo, durante las discusiones del Congreso de Cúcuta, el abogado Miguel Tobar había señalado que no había delito que no atacara el orden social ${ }^{46}$, lo que de hecho era visible en la práctica judicial de la capital: en los juicios de las décadas de 1820 y 1830 se observa que, para los fiscales en sus acusaciones y alegatos, en términos generales, los hurtos constituían un ataque contra la sociedad entera.

Más allá de los cambios semánticos alrededor del orden, el problema del trastorno en el orden social derivado la Independencia se manifestaba no solo en los temores de algunos ciudadanos ${ }^{47}$, sino que además iba apareciendo en las medidas de política penal, en primer lugar, bajo su aspecto negativo, el desorden. Así, el motivo de la ley del 14 de octubre 1821 contra "conspiradores y perturbadores de la paz pública" era la desorganización social, consecuencia de la Revolución, que había hecho aumentar los delitos.

Pero los gobernantes republicanos venían entendiendo el orden como la seguridad de los derechos individuales, recogiendo así las ideas ilustradas y liberales que fundamentaban el orden social en términos individualistas a partir del presupuesto del contrato como origen de la sociedad ${ }^{48}$. Esto explica que la ley contra ladrones de

44 Gutiérrez Ardila, Daniel. “Colombia/Nueva Granada”. En Fernández Sebastián, Javier, ob. cit., p. 135.

45 Expresión al parecer tomada de Gaetano Filangieri, para quien las leyes se encargaban de asegurar la "tranquilidad pública y privada" (indicando así el vínculo entre ley y orden).

46 "Sesión del día 13 de agosto". En Restrepo Piedrahita, Carlos (prólogo). Actas del Congreso de Cúcuta. Bogotá, Fundación Francisco de Paula Santander, 1990.

47 Colmenares, Germán, ob. cit., pp. 226 y 227.

48 Por ejemplo, según Estanislao Vergara en 1820, "los derechos de la sociedad [eran] un producto de los derechos individuales". "Memoria del encargado del Despacho del Interior y Justicia del Departamento de Cundinamarca, presentada a su excelencia el Vicepresidente el 31 de diciembre". Vergara, Estanislao, ob. cit., p. 31. Como señala Anitua, Gabriel Ignacio, "La pretensión de justificar jurídicamente actuaciones políticas (como el castigo) se remonta a la idea de contrato, que a su 
1826, a diferencia de la de 1821, estuviera motivada ya no por la "desorganización social" derivada de la revolución sino por los ataques "a la propiedad y seguridad del pacífico ciudadano".

Sea cual fuera la denominación concreta en cada caso, el problema del orden siguió siendo una preocupación constante para los gobernantes incluso después de la disolución de República de Colombia en $1830^{[49]}$. Por ejemplo, el propio Francisco de Paula Santander aseguraba que los efectos de la Ley de 19 de noviembre de 1831 refrenaban "por el temor las pasiones exaltadas" y prevenían "la repetición de excesos funestos al orden social" 50 . Más adelante, el secretario de Estado Lino de Pombo se referiría, en la sección de seguridad pública de su informe de 1835, a las penas que habían recibido los delincuentes, y que

exceptuando los muy pocos actos de esta naturaleza que han ocurrido, la seguridad individual no ha sufrido en el país; y las vidas y propiedades han gozado de protección en todo el ámbito de la Nueva Granada, sin otro apoyo que la moralidad y la suavidad de costumbres de la mayoría de ciudadanos, y el respecto que se profesa a las leyes y autoridades ${ }^{51}$.

Esta opinión, de nuevo, recogía una idea sobre el orden social en función de la seguridad de los derechos individuales. La defensa social como fundamento del castigo era, al mismo tiempo, la defensa de esos derechos individuales. En la práctica judicial, el criterio de la defensa social seguía apareciendo expresada en el carácter de atentado contra el cuerpo social más que contra los afectados individualmente considerados que tenían los hurtos, particularmente en los discursos de los fiscales, como se indicó previamente.

Así como los significados del orden se estaban transformando, algo similar comenzó a suceder con la forma de entender la función de la administración de justicia, aunque hubiera continuidades. Durante el virreinato la administración de justicia tendía a basarse en la noción tradicional de la justicia conmutativa del Digesto (mantener a cada cual en su Derecho) recogida en la cultura jurídica castellana. En 1820, por

vez se origina en las concepciones individualistas ilustradas que ponen su fe en la razón humana". "Contradicciones y dificultades de las teorías del castigo en el pensamiento de la ilustración". Ob. cit., p. 14.

49 Pombo, Lino de. "Exposición del secretario de Estado, en el despacho del interior y relaciones exteriores del gobierno de la Nueva Granada al congreso constitucional del año de 1837”. En Gómez Rodríguez, Luis Horacio (comp.), ob. cit., t. v, p. 278.

50 Santander, Francisco de Paula. "Mensaje del presidente del Estado de la Nueva Granada al Congreso en la sesión de 1833”. En Gómez Rodríguez, Luis Horacio (comp.), ob. cit., t. III, p. 106.

51 Pombo, Lino de. "Exposición del secretario de Estado, en el despacho del interior y relaciones exteriores del gobierno de la Nueva Granada, al congreso constitucional del año de 1835, sobre los negocios de su departamento”. En Gómez Rodríguez, Luis Horacio (comp.), ob. cit., t. IV, p. 216. 
ejemplo, el secretario de Estado Estanislao Vergara, encargado del despacho del interior y de justicia de Cundinamarca, identificaba esa actividad con el mantenimiento de los derechos de cada uno, y conservar ilesos los de todos, puesto que los hombres se habían reunido en sociedad para evitar la violencia y buscar "un abrigo contra la injusticia" ${ }^{52}$.

Por su parte, en la definición del poder judicial que aparece en el Congreso de Cúcuta se observa la superposición de criterios legalistas con otros más tradicionales sobre la justicia:

El Poder Judicial, donde los asaltos de la intriga pierden toda su fuerza y el rico todo su ascendiente; adonde nadie puede llegar con rostro sereno si no va revestido con todos los simples adornos de la justicia, está destinado a dirimir imparcialmente vuestras contiendas, reprimir al malvado y favorecer la inocencia; en tan respetuoso lugar rinden todos homenaje a la ley; y allí veréis las pasiones desarmadas, cortadas las tramas del artificio y descubierta la verdad ${ }^{53}$.

Esta concepción de la justicia como actividad basada en la ley al servicio de los derechos de los individuos se observa más adelante en un informe del secretario de Estado Alejandro Vélez de 1831, según el cual una buena administración de justicia era

la primera de las necesidades de una nación, porque en ella están vinculadas las seguridades de los derechos más preciosos de sus miembros. El honor, la vida, las propiedades y la libertad misma, están confiadas a la decisión de los juzgados y tribunales, y las determinaciones de estos, aseguran o destruyen las garantías individuales. En nada han puesto más cuidado nuestros congresos que en mejorar esta administración ${ }^{54}$.

Asimismo, el secretario del interior Francisco Soto afirmaba en 1833 que en la administración de justicia estaban "altamente interesados los pueblos, porque su buen desempeño es la salvaguardia de los derechos civiles e individuales y constituye la libertad práctica de los asociados" 55 . De todos modos, el modelo tradicional de justicia conmutativa seguía apareciendo en la década 1830, como se ve en un acuerdo de la Alta Corte de Justicia en que señalaba que los jueces y subalternos se empleaban

52 Vergara, Estanislao, ob. cit., p. 24.

53 “Alocución del Congreso a los Habitantes de Colombia”. En Restrepo Piedrahita, Carlos (prólogo), ob. cit.

54 Vélez, Alejandro. "Exposición que el ministro secretario de Estado en el despacho del interior y justicia del gobierno de la República, presenta a la convención granadina de 1831, sobre los negocios de su departamento". En Gómez Rodríguez, Luis Horacio (comp.), ob. cit., t. III, p. 34.

55 Soto, Francisco, ob. cit., p. 123. 
en distribuir " a cada uno lo suyo o le pertenecía por derecho, frenar las pasiones, y conservar la armonía del orden social aplicando las disposiciones legales a los hechos" 56 . Este texto judicial expresaba la mayor lentitud con que ocurrían los cambios en la práctica judicial, en este caso discursivos, en comparación con los políticos.

Otro cambio que comenzó a tener lugar en el periodo de la República de Colombia fue la desaparición de la justicia vindicativa (expresión propiamente penal de la justicia durante el virreinato) en los discursos penales gubernamentales, aunque siguiera presente en la práctica judicial. El jurista ilustrado español José Marcos Gutiérrez, por ejemplo, ya había argumentado que las leyes no debían contener pasiones como la venganza y que todas las expresiones relacionadas con la vindicta pública debían desterrarse de las causas criminales ${ }^{57}$. En la Colombia de la década de 1820 , el término tampoco aparecía en las discusiones constitucionales de 1821 ni en los informes gubernamentales sobre administración de justicia. Sin embargo, en la práctica judicial, en la que los cambios ocurrían más lentamente que las transformaciones del lenguaje jurídico-político en los niveles superiores de la incipiente organización política, el término vindicta pública seguiría vigente durante las primeras décadas de la República.

En 1826, por ejemplo, el fiscal de la Corte Superior Departamental de Cundinamarca observaba que la escasez de papel sellado en algunas regiones acarreaba "el atraso del castigo de los delincuentes, que interesa a la vindicta pública siga a la comisión del delito" 58 . Este criterio para el castigo seguía apareciendo en los juicios criminales en la década de 1830, como puede verse en un caso de 1832 en que el defensor señalaba que

así como la vindicta pública se interesa en que se persigan y castiguen los criminales, así también al buen orden de la sociedad y las garantías individuales del ciudadano exigen imperiosamente que para ello se observen las fórmulas tan sabiamente prescritas por nuestras leyes, de otro modo veríamos a cada paso castigar con una misma pena delitos de diferente gravedad ${ }^{59}$.

El texto llama la atención no solo por la persistencia del uso de dicha noción, sino además por la asociación que hacía a renglón seguido entre el orden social y las garantías individuales, lo cual muestra un cambio dentro de una continuidad en el discurso. Además, para el defensor, el reo era un ciudadano con derechos que también tendrían que ser respetados al seguir las formalidades de la ley, lo que contrasta con

56 AGN, Sección República, Juzgados y Tribunales, legajo 23, f. 325v.

57 Gutiérrez, José Marcos. Práctica Criminal de España,t. III. Madrid, Imprenta de Fermín Villalpando, 1828, pp. 32-34.

58 AGN, Sección República, Juzgados y Tribunales, tomo 21, f. 132r.

59 AGN, Sección República, Asuntos Criminales, legajo 71 ff. 263-291. 
la tendencia, de nuevo proveniente el virreinato, a apelar ante todo a la misericordia de los jueces en beneficio de los reos.

Más adelante, durante los debates de 1836 en el Congreso sobre el Código Penal, se observa una actitud general en contra de la vindicta pública como justificación para las penas. Por ejemplo, uno de los participantes argumentaba que la pena no tenía "por objeto vengar al infeliz ultrajado por el criminal, ni el castigo se impone para reparar el mal hecho, sino para contener al reo y a sus semejantes por medio del temor" 60 . Esta posición terminó prevaleciendo en el código de 1837, puesto que no incluía la vindicta pública como justificación de las penas. Así, al menos en el nivel legislativo, ese criterio desapareció del discurso estatal.

\section{LA LEGISLACIÓN CONTRA LADRONES (1819-1837)}

Durante la República de Colombia, como indiqué, prevaleció una tendencia represiva en las leyes contra ladrones, con castigos duros que llegaban a la pena de muerte. Esta tendencia contrasta con el discurso garantista de la Constitución de 1821, que veremos más adelante. Por el contrario, la ley del 6 de abril de 1836 buscó soluciones más moderadas y de índole utilitaria a ese problema, lo cual tendría continuidad en el Código Penal del año siguiente.

\subsection{La ley del 17 de julio de $\mathbf{1 8 2 0}$}

El gobierno sancionó en julio 17 de 1820 la primera ley para endurecer el castigo contra los ladrones a partir del problema del aumento de los robos en la capital, aunque la preocupación por los delitos ya estuviera adquiriendo dimensiones nacionales visibles en los debates constitucionales de Cúcuta. Por su parte, Estanislao Vergara, encargado del Despacho del Interior y Justicia del Departamento de Cundinamarca, justificaba dicha ley en su informe de ese año en unos términos que muestran el vínculo que veía entre los derechos individuales y su defensa a través del castigo a los delitos contra la propiedad:

Son los derechos de la sociedad un producto de los derechos individuales; y el gobierno, que cuida de la conservación de los unos, debe procurar igualmente que se mantengan ilesos los otros. El de propiedad y el de seguridad estaban atacados por algunos malvados que escalaban las casas, violentaban y maltrataban a los dueños y les pillaban sus bienes ${ }^{61}$.

De acuerdo con Vergara, el mal de los robos se sufría en la capital "y sus arrabales, a pesar de la vigilancia de los magistrados y del celo de las patrullas" y era necesario

60 “Sesión de la noche del 18 de marzo de 1836”. En Cámara del Senado, ob. cit., p. 124.

61 Vergara, Estanislao, ob. cit., p. 32. 
un "crudo escarmiento" para contener esos delitos ${ }^{62}$. Esa fue la razón por la que Santander determinó en la mencionada ley del 17 de junio de ese año que se condenara a muerte, luego de un proceso sumario, a los ladrones que hubieran cometido el crimen con escalamiento de casa y forzando a los dueños. A juicio de Vergara, la publicación de esa providencia sirvió para cesaran y se contuvieran "absolutamente unos atentados que por su cualidad y circunstancias eran de la mayor gravedad" 63 .

Esta norma, de todos modos, solo apareció muy rara vez en los procesos por hurtos, que siguieron desarrollándose de la forma ordinaria que venía desde el virreinato. En otras palabras, hasta el momento no hay evidencia de condenados a muerte en virtud de esta norma. El texto de dicha ley contra ladrones de 1820 era el siguiente:

Siendo muy frecuentes los robos que se cometen en la ciudad y pueblos circunvecinos perforándose las casas y maltratándose los dueños con infracción de los derechos de seguridad y propiedad, que todos tienen en sociedad, y que el Gobierno debe proteger; para que los delincuentes se contengan, y la vindicta pública no padezca, ha venido en decretar

1. Todos los ladrones que fueren aprendidos, a quienes por una sumaria información les fuere plenamente justificado el delito, previa la confesión del Reo, se procederá inmediatamente a imponerle la pena de muerte.

2. La sentencia se consultará con la Alta Corte de Justicia en el mismo día que se pronunciare, y dentro de seis estará despachada la consulta ${ }^{64}$.

La parte en cursivas muestra claramente el vínculo entre el mantenimiento del orden y la protección de los derechos individuales "de seguridad y propiedad" que aparece en el discurso gubernamental de la época. Al mismo tiempo, la norma seguía usando la expresión vindicta pública, referida a un predominio de la venganza social como criterio del castigo para los ladrones. En este sentido recoge el discurso jurídicopenal prevaleciente en el virreinato de la Nueva Granada. También llama la atención que, a pesar de la celeridad que proponía para el sumario, al mismo tiempo tampoco rompía con la costumbre castellana de consultar con el superior (la Real Audiencia, y en este caso la Alta Corte) las sentencias con pena corporal, una obligación que retrasaba los castigos en la práctica. Recordemos que en el virreinato era obligatorio, según la costumbre, que los jueces de primera instancia consultaran siempre en segunda instancia las sentencias por delitos con pena corporal, como los hurtos.

62 Ibíd., p. 31.

63 Ibíd., p. 31.

64 "Ley de Julio 17 de 1820. Sobre que a los ladrones debe imponérseles la pena capital". AGN, Sección República, Libros Manuscritos y leyes Originales de la República, tomo 7 Secretaría del Interior y de Justicia, f. 20v y 21r (las cursivas son mías). 
Así pues, esta norma, al establecer una solución a un problema nuevo, seguía recogiendo cultura jurídica vigente.

\subsection{La ley del 14 de octubre de 1821}

El año siguiente, la ley del 14 de octubre de 1821 fue discutida durante el Congreso de Cúcuta. Esta norma tuvo su origen en la solicitud del gobernador de Casanare para que se le permitiera imponer penas capitales a los cuatreros y bandidos que se habían levantado en aquella provincia, "estando evacuada la sumaria, por ser este el medio más seguro para extirpar aquella clase de malhechores que con motivo de la guerra se ha aumentado en dicha provincia" ${ }^{65}$. El vicepresidente Santander y el secretario de Gobierno Restrepo trasmitieron dicha solicitud al Congreso para la redacción de la ley.

Con esta norma el Gobierno buscaba que el procedimiento contra estos delincuentes fuera más expedito que el que el juicio ordinario que venía teniendo lugar en la práctica según la costumbre castellana. Por ejemplo, la discusión alrededor del término de prueba se enfocaba en que no excediera de ocho días comunes (que contrastan con el de hasta 90 que muchas veces obtenían los procuradores en la práctica) y así quedó en la norma. Luego de este plazo, el tiempo para determinar la causa era de 24 horas ${ }^{66}$. La ley establecía un procedimiento de máximo 17 días incluyendo la consulta de la sentencia al gobernador, y de 26 si se interponía el recurso de súplica.

Esta norma establecía el "modo de proceder contra los conspiradores y perturbadores de la tranquilidad pública". Su propio título indica que se trata de una ley de procedimiento, pero al mismo tiempo se trataba de una disposición con contenido jurídico sustantivo al señalar los delitos que debía castigar y sus penas. Recordemos, de nuevo, que este es un periodo previo a la codificación nacional y a la separación legislativa entre unas normas penales con contenido sustantivo (es decir, los delitos y las penas), y unas de procedimiento.

La finalidad de esta forma aparecía explícita en un preámbulo, lo cual recuerda, por ejemplo, la estructura de las cédulas reales. Su objetivo era "facilitar la prontitud del castigo", cortar "el mal", y evitar el "contagio" a otras partes de la República. El propio legislador reconocía la impunidad y dificultad para castigar a quienes se aprovechaban de ella "para trastornar el orden establecido", es decir, las limitaciones que tenía el gobierno para imponer el orden después de la guerra. Al mismo tiempo reconocía que la "desorganización social" era "consecuencia indispensable" de la revolución y la guerra civil, lo cual había "aumentado la audacia de los facinerosos" haciendo frecuente ciertos delitos "principalmente en nuestros vastos y yermos despoblados".

65 “Sesión del día 12 de julio de 1821”, en Restrepo Piedrahita, Carlos (prólogo), ob. cit.

66 "Acta del día 8 de octubre de 1821”,p. 655; "Acta del día 10 de octubre 1821”, p. 664; "Acta del día 12 octubre de 1821 ”, p. 678 . Ibíd. 
Quienes cometían esos "ciertos delitos" eran los mencionados conspiradores y "perturbadores de la tranquilidad pública"; dentro de estos últimos la ley incluía a los "bandoleros y salteadores que salen a los caminos públicos o a las poblaciones, los que comentan hurtos en despoblados y cualesquiera que turben la paz pública en asonadas o tumultos" $"$.

Esta norma incluía un procedimiento especial contra los "conspiradores contra la República, los bandoleros y salteadores que salen a los caminos públicos o a las poblaciones, los que cometan hurtos en despoblados, y cualesquiera otros que turben la paz pública con asonadas o tumultos". Todos estos quedarían sujetos a la jurisdicción común ordinaria, sin que valiera fuero en contrario, lo que sin duda iba dirigido a incluir dentro del ámbito de la justicia ordinaria incluso a los delitos de esa clase cometidos por curas o militares, que tradicionalmente tenían su propia jurisdicción.

Esta ley se refería explícitamente a la competencia para conocer de los juicios, sino que usaba el término genérico de "juez”, y en el artículo 6 señalaba que la sentencia sería con dictamen de asesor. Esto indica que la competencia seguía siendo de los alcaldes ordinarios.

La estructura del proceso establecido en esta ley era la siguiente:

\begin{tabular}{|c|c|c|}
\hline $\begin{array}{c}\text { Etapa } \\
\text { procesal }\end{array}$ & Actuación & Tiempo \\
\hline \multirow{2}{*}{ Sumario } & Información sumaria o captura in flagranti & \multirow{2}{*}{ Indeterminado } \\
\hline & Prisión del reo & \\
\hline $\begin{array}{l}\text { Plenario } \\
1\end{array}$ & $\begin{array}{l}\text { "Conforme a los artículos } 159 \text { y } 160 \text { de la Consti- } \\
\text { tución, el juez procederá inmediatamente a evacuar } \\
\text { todas las diligencias para el complemento del sumario } \\
\text { y comprobación del delito." }\end{array}$ & \multirow{3}{*}{$\begin{array}{c}24 \text { horas } \\
\text { "si fuere posible" }\end{array}$} \\
\hline 2 & Confesión al reo & \\
\hline 3 & Nombramiento de fiscal y defensor del reo & \\
\hline 4 & Apertura de la causa a prueba & \multirow{2}{*}{ Máximo ocho días } \\
\hline 5 & Traslado por parte del juez al fiscal y al reo & \\
\hline 6 & Evacuación del traslado por los dos anteriores & Máximo 24 horas \\
\hline
\end{tabular}

67 Ley de 14 de octubre de 1821. En Sala de negocios generales del Consejo de Estado. Codificación nacional de todas las leyes de Colombia, v. 1. Bogotá, Imprenta Nacional, 1924, pp. 140 y 141. 


\begin{tabular}{|c|c|c|}
\hline $\begin{array}{c}\text { Etapa } \\
\text { procesal }\end{array}$ & Actuación & Tiempo \\
\hline \multirow[b]{2}{*}{7} & $\begin{array}{l}\text { a. Sentencia, con citación de los interesados y de } \\
\text { acuerdo con el asesor. }\end{array}$ & Tres días \\
\hline & $\begin{array}{l}\text { b. Remisión de la causa por posta al letrado conve- } \\
\text { niente el mismo día de terminar la causa si no hubiere } \\
\text { asesor en el lugar. }\end{array}$ & Tres días \\
\hline 8 & $\begin{array}{l}\text { Consulta incontinenti al gobernador de la provincia, } \\
\text { quien con dictamen de asesor la confirma. }\end{array}$ & Máximo tres días \\
\hline \multirow[t]{2}{*}{9} & $\begin{array}{l}\text { a. Si la sentencia del gobernador fuere confirmatoria } \\
\text { o revocatoria en favor del reo, se devolverá inmedia- } \\
\text { tamente el proceso al juez interior para que la ponga } \\
\text { en ejecución. }\end{array}$ & Inmediatamente \\
\hline & $\begin{array}{l}\text { b. Si fuera revocatoria agravando la pena, se podrá } \\
\text { suplicar por el reo dentro de } 24 \text { horas para la Corte } \\
\text { superior. }\end{array}$ & 24 horas \\
\hline 10 & $\begin{array}{l}\text { La Corte Superior de justicia pronunciará dentro } \\
\text { de seis días el juicio de súplica, el cual se llevará a } \\
\text { efecto por el juez de primera instancia, a quien se } \\
\text { devolverá el proceso. }\end{array}$ & Seis días \\
\hline
\end{tabular}

Lo anterior indica que el proceso habría que tenido que durar máximo 23 días una vez formado el sumario.

\subsection{La ley del 3 de mayo de 1826}

Luego de las leyes de 1820 y 1821, la más importante de estas normas represivas fue la del 3 de mayo de 1826, expedida a partir de consideraciones sobre el desorden e inseguridad de la capital, de un modo similar a la de 1820. Según la Corte Suprema, no solo había ladrones dedicados al hurto por simple apropiación de la cosa, sino que también había grupos de ladrones que "asaltaban con mano armada la vida y propiedades de los ciudadanos" $" 68$. Esto indica la gravedad que había adquirido el problema, puesto que durante el periodo colonial los hurtos violentos eran extremadamente raros.

68 "Informe que ha dado la Corte Superior de Justicia de estos departamentos al Supremo Poder Ejecutivo sobre la reforma de las leyes orgánicas de procedimiento civil, y contra los ladrones, a consecuencia del anónimo inserto en El Conductor n. ${ }^{\circ} 27$ ”. En AGN, Sección República, Juzgados y tribunales, legajo 22, s. n. 
El cumplimiento de la nueva ley, el pronto despacho de las causas criminales y el castigo de los delincuentes eran tres preocupaciones del Gobierno de Santander. En 1827, aunque los condenados por delitos contra la propiedad en virtud de esta ley se habían incrementado considerablemente, José Manuel Restrepo se seguía lamentando del mal que significaba esa delincuencia, que a su juicio continuaba a pesar de la dureza de los castigos señalados en la ley. Para Restrepo, una razón podía ser que no se hubiera "ejecutado con el debido rigor por los jueces que han de imponer el castigo"69.

Restrepo añadía que, a pesar de las reformas judiciales de 1821 y 1825, aún existían dificultades que retardaban "la conclusión de los procesos" y facilitaban a los reos eludir las penas. Para Restrepo, la causas de que los ladrones se hubieran "multiplicado en algunos puntos de la República" eran, en primer lugar, los defectos de las leyes españolas que todavía eran "la base de nuestra legislación criminal"; en segundo lugar, la poca seguridad de las cárceles; en tercer lugar, "el descuido a veces punible de los jueces de primera instancia para aprehender a los reos e imponerles el condigno castigo"; y, finalmente, la falta de presidios o lugares en que se cumplieran las penas ${ }^{70}$.

Esa fue una de las razones por las que el Gobierno pidió un informe a la Corte Superior Departamental de Cundinamarca sobre el cumplimiento y los efectos de la ley contra ladrones del 3 de mayo de 1826 (petición que ejemplifica además la vigilancia sobre el Poder Judicial que los miembros del Ejecutivo decidieron asumir). La respuesta de la Corte en 19 de febrero de ese año muestra cómo dicha norma fue efectiva porque no rompía con la costumbre judicial vigente. De acuerdo con la Corte, dicha ley designaba las "fórmulas principales" del procedimiento, lo cual evitaba la necesidad de consultar otras leyes excepto sobre "algunos puntos comunes del Derecho". Por esta razón, los alcaldes y escribanos, que no eran letrados, se podían formar por ellos mismos los procesos sin "consejo de abogados" ni la necesidad de consultar la "antigua legislación"71.

La Corte argumentaba, además, que los procesos criminales se habían incrementado no porque hubiera crecido el número de los ladrones, sino porque gracias a la simplificación del procedimiento de la nueva ley aquellos eran más perseguidos. Para la Corte, lo anterior había significado una ventaja puesto que la mayoría de las veces había despachado las causas en el término de seis días señalado por la ley. Sin embargo, aclaraba, no ocurrió en todos los casos, pues para ello habrían tenido que dejarse sin despachar otros procesos civiles y criminales que no podían abandonarse por su gravedad. Por anterior, la Corte insistía en una observación que había hecho previamente al Gobierno sobre la insuficiencia de un solo tribunal para Cundinamarca

69 Restrepo, José Manuel, ob. cit., p. 264.

70 Restrepo, José Manuel, ob. cit., p. 264.

71 AGN, Sección República, Juzgados y tribunales, legajo 22, f. 244 v. 
y Boyacá para cumplir con los fines del gobierno frente a los ladrones ${ }^{72}$ (puesto que, como indiqué, todas las sentencias con pena corporal debían ser consultadas ante dicha corte). Lo anterior sigue mostrando el peso de la costumbre judicial en medio de las reformas legislativas, aunque afectara la efectividad en el castigo a los delincuentes buscada por el gobierno.

Más adelante, el 16 de mayo de 1827, la Corte redactó un nuevo informe sobre la ley contra ladrones y la ley de procedimiento civil a raíz de un anónimo publicado en El Conductor (n. ${ }^{\circ}$ 27). En este documento la Corte insistía en la imposibilidad de que un solo tribunal despachara todas las causas pendientes de dos departamentos a pesar de sus esfuerzos en ese sentido. A esa fecha, informaba, se habían sentenciado 47 causas criminales.

El mencionado anónimo, con fecha 26 de abril de 1827, resulta de interés para mostrar algunas de las dificultades que existían para la administración de justicia más allá de las indicadas por la Corte. Su autor se refería a una causa por robos seguida el año anterior por el juzgado municipal de La Mesa (provincia de Cundinamarca) contra varios sujetos, que se había dilatado debido a que el asesor de la causa se había llevado los autos desde diciembre para emitir su dictamen, y a la fecha no los había devuelto $^{73}$. Esto motivó que el juez, compadecido de los procesados que se hallaban en el único calabozo de la cárcel de ese pueblo, se viera en la necesidad de ponerlos en libertad bajo fianza. Lo anterior, continuaba el anónimo, había causado en el pueblo y sobre todo entre quienes conocían la ley del 3 de mayo contra vagos y ladrones,

Todo el escándalo, crítica y murmuración que reservo a la consideración de V. y por esta razón no he podido menos que tomar la pluma para comunicarle estas cositas que en mi humilde concepto deben merecer la atención del gobierno, igualmente que la de V. que trabaja infatigable por el sostenimiento de nuestras instituciones políticas, o de las muy sabias y brillante constitución y leyes de Colombia ${ }^{74}$.

El autor del texto no se limitaba a referir este caso, sino que además señalaba que en los juzgados municipales del cantón se habían seguido varias causas por delitos graves con todo "el trabajo, dificultades y molestias" experimentadas en los pueblos que no contaban con peritos en negocios judiciales ni con los recursos de la capital. Las sentencias se habían pronunciado asesoradas de letrados, para luego ser remitidas a consulta a la Corte Suprema de Justicia, y sin embargo estas resoluciones no habían regresado, por lo que los "infelices delincuentes" padecían las mismas penas que los anteriores en el calabozo, lo cual incluso había llevado a uno de ellos a la muerte.

72 AGN, Sección República, Juzgados y Tribunales, tomo 22, f. 244 y 247.

73 Estas demoras eran comunes en la práctica judicial.

74 “Señor editor del Conductor. Mesa abril 26 de 1827”. En El Conductor n. ${ }^{\circ}$ 27, mayo 1. ${ }^{\circ}$ de 1827, p. 4. 
El autor señalaba concretamente cuatro causas que no regresaron después de haber ido a consulta entre junio y octubre de 1826.

La Corte informaba que solo tres causas, de las 22 que habían llegado para consulta en los 48 días entre el primero de enero y la fecha de la comunicación, habían concluido con la pena de muerte, de las cuales dos estaban en estado de "verse en estos días", y la otra ya debía haberse ejecutado en Ubaté. En las otras 19 causas, o no había habido "la calificación de [...] los artículos 26 y 27 de dicha ley para imponer dicha pena", o las circunstancias que constituían esa calificación no habían sido "suficientemente probadas". La conclusión de la Corte era que, a pesar de las ventajas de dicha ley, tenía también "defectos sustanciales" y necesitaba de reformas, que propondría más adelante al Gobierno ${ }^{75}$.

Los magistrados se referían además a los mismos "defectos" de la ley que habían mencionado en su informe de febrero. En primer lugar, señalaban que la ley había dejado la práctica de las primeras diligencias a los alcaldes rurales (es decir, los parroquiales que reemplazaron a los pedáneos en 1825), que generalmente no entendían de rutinas judiciales, y entre los que muchos ni siquiera podían leer ni escribir, y que habían producido un exceso o "multitud de sumarios", o "más bien una aglomeración de papeles sin orden, formados por cualquiera sospecha infundada contra ladrones hasta por el hurto de una gallina, y que no conteniendo otra cosa que confusión, se ha visto la corte superior en la precisión de mandar devolverlos para su reposición"76.

La Corte atribuía además a los cortos términos de la ley los defectos que encontraba en las causas y que las viciaban "en todo o en parte". Para los magistrados, seis días eran demasiado pocos para que se determinara en último fallo con la "detenida meditación” que exigía la gravedad de un negocio que podía implicar una condena a muerte.

La ley del 3 mayo de 1826, a pesar de su importancia para el gobierno e incluso para el público, como pudo verse arriba, era una disposición expedida en virtud de una situación especial más que una medida pensada a largo plazo, aunque no mencionara ese punto. Un texto de 1831 ayuda a entender esta característica. El defensor en una causa contra ladrones argumentaba que en el año de 1826

eran tantos y tan repetidos los robos que se cometieron en esta capital, con fracturas y violencias por los desertores y otros hombres que, habiendo, por

75 AGN, Sección República, Juzgados y Tribunales, tomo 22, f. 247r. y v.

76 Corte Superior de Justicia de Cundinamarca. Informe que ha dado la Corte Superior de Justicia de estos departamentos al Supremo Poder Ejecutivo sobre la reforma de las leyes orgánicas de procedimiento civil, y contra ladrones, a consecuencia del anónimo inserto en El Conductor número 27. Bogotá, Imp. de P. C., 1827, p. 9. Firman Gregorio de Jesús Fonseca y José Mariano Azero, secretario interino. 
la mudanza de gobierno, perdido su modo de subsistir se reunían a arbitrar aquel inicuo modo de adquirir que hallándose reunida la legislatura se vio en la necesidad de dictar la ley de 1 de mayo [sic] de dicho año, ley de circunstancias. Ella en su efecto tiene su principio con estas palabras "considerando que por una consecuencia de la dilatada guerra que ha sufrido la república, cierta clase de hombres etc.". Por estas palabras se viene en conocimiento que la intención del legislador no fue hacer una novedad en las leyes relativas a la clase de hurtos o robos que no eran una precisa consecuencia de la guerra, sino refrenar la frecuencia y escandalo con que se atacaba en aquellos días la propiedad y seguridad del pacifico ciudadano por hombres reunidos en número de dos o más ${ }^{77}$.

La parte final del anterior texto ilustra así el carácter especial de la ley contra ladrones de 1826. Sin embargo, esta disposición siguió siendo el criterio procesal y sustantivo adoptado por los jueces de la región de la antigua jurisdicción de Santa Fe en las causas por hurtos hasta que el Código Penal de 1837 comenzó a aplicarse en 1838.

Más allá del vínculo que tienen con las circunstancias del periodo, las leyes de 1820 , 1821 y 1826 expresan, en términos de su estructura y contenido, novedades y cambios: se trata de disposiciones cuya estructura "casuista" recuerda la de las antiguas cédulas reales. También se trata de normas que incluyen aspectos de índole sustantiva y procesal, a diferencia de los códigos que más adelante adoptaría el gobierno. Al mismo tiempo, estas normas recogen novedades importantes como la noción de derechos individuales.

La ley del 3 de mayo de 1826, a diferencia de las anteriores, sí señala la competencia de forma explícita en su artículo 1. ${ }^{\circ}$ :

En los delitos de hurto o robo, los jueces letrados y los alcaldes municipales y parroquiales procederán al sumario y primeras diligencias para la averiguación del delito y sus autores, a la aprehensión de estos y a la continuación de la causa hasta dictar sentencia, aun en los días festivos y sin interrupción de momentos $[\ldots]^{78}$.

El tiempo máximo de duración de este proceso debía ser de 26 días, aunque no siempre se cumplían, lo que se debía ante todo a las demoras de la Corte Superior para despachar las causas que llegaban a ella en apelación o consulta.

77 AGN, Sección República, Asuntos criminales, legajo 67, ff. 720-749.

78 “Ley de 3 mayo de 1826”. En Sala de Negocios Generales del Consejo de Estado, ob. cit., v. 2, p. 313. 


\begin{tabular}{|c|c|c|c|}
\hline \multicolumn{2}{|c|}{$\begin{array}{c}\text { Etapa } \\
\text { procesal }\end{array}$} & Actuación & Tiempo \\
\hline \multirow{6}{*}{ 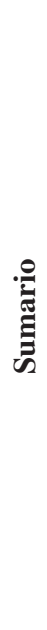 } & 1 & $\begin{array}{l}\text { Luego de recibir noticia sobre un hurto o robo, el juez } \\
\text { o alcalde debe dirigirse al sitio donde ocurrió, acom- } \\
\text { pañado del procurador municipal, en las ciudades } \\
\text { y villas, o del síndico parroquial en las parroquias. }\end{array}$ & \multirow{6}{*}{ Indeterminado } \\
\hline & 2 & $\begin{array}{l}\text { (El escribano) debe hacer una razón circunstanciada } \\
\text { de las señales, efectos o rastros del sitio del delito. }\end{array}$ & \\
\hline & 3 & Reconocimientos por los peritos (si hay). & \\
\hline & 4 & $\begin{array}{l}\text { Recoger las armas, instrumentos o cosas que hayan } \\
\text { delatado los delincuentes, y examinar bajo juramento } \\
\text { a los testigos. }\end{array}$ & \\
\hline & 5 & Detener a los sospechosos. & \\
\hline & 6 & $\begin{array}{l}\text { Tomar declaración a los habitantes de la casa o el lugar, } \\
\text { y si resultan cómplices o auxiliadores o receptadores, } \\
\text { también serán detenidos. }\end{array}$ & \\
\hline \multirow{12}{*}{ 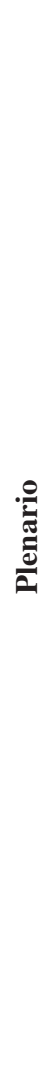 } & 1 & $\begin{array}{l}\text { Recibir "exposiciones instructivas" a los reos, cóm- } \\
\text { plices y auxiliadores. }\end{array}$ & \multirow{3}{*}{48 horas } \\
\hline & 2 & $\begin{array}{l}\text { Remitir los reos al juez letrado o alcalde municipal } \\
\text { (si no fueron ellos quienes procedieron). }\end{array}$ & \\
\hline & 3 & $\begin{array}{l}\text { Dictar auto de prisión con arreglo al artículo } 161 \text { de } \\
\text { la Constitución*. }\end{array}$ & \\
\hline & 4 & $\begin{array}{l}\text { Pasar el proceso al procurador municipal, que hará de } \\
\text { fiscal, para acusar o expresar el concepto que crea jus- } \\
\text { to. Si pide diligencias, se practicarán en el mismo día. }\end{array}$ & \multirow{4}{*}{24 horas } \\
\hline & \multirow{2}{*}{5} & El fiscal acusa. & \\
\hline & & El fiscal no acusa. Los reos serán puestos en libertad. & \\
\hline & 6 & $\begin{array}{l}\text { Si el fiscal ha acusado, el juez tomará confesión } \\
\text { a los reos, haciendo lectura del artículo } 165 \text { de la } \\
\text { Constitución**. El reo podrá escoger defensor o } \\
\text { defenderse por sí. }\end{array}$ & \\
\hline & 7 & Recibir la causa a prueba. & $\begin{array}{l}6 \text { días. Máximo } 12 \\
\text { si hay que practicar } \\
\text { pruebas en otro lugar }\end{array}$ \\
\hline & 8 & Traslado al fiscal y al reo. & 24 horas \\
\hline & \multirow[b]{2}{*}{9} & Sentencia. & \multirow[b]{2}{*}{3 días } \\
\hline & & $\begin{array}{l}\text { Si no hay asesor, remitir al letrado más cercano } \\
\text { (no aplicaría para el juez letrado). }\end{array}$ & \\
\hline & 10 & Consulta a la Corte Superior. & 6 días \\
\hline
\end{tabular}


* Artículo 161. Para que un ciudadano pueda ser preso se necesita: 1. Una orden de arresto formada por la autoridad a quien la ley confiera este poder; 2. Que la orden exprese los motivos para prisión; 3. Que se le intime y dé una copia de ella.

** Artículo 165. En cualquier tiempo en que parezcan desvanecidos los motivos que hubo para el arresto, detención o prisión, el arrestado será puesto en libertad. También obtendrá dando fianza, en cualquier estado de la causa en que se vea que no pudo imponérsele pena corporal. Al tiempo de tomar confesión al procesado que deberá ser a lo más dentro del tercero día, se le leerán íntegramente todos los documentos y las declaraciones de los testigos, con los nombres de éstos; y si por ellos no los conociere, se le darán todas las noticias posibles para que venga en conocimiento de quiénes son.

Como puede verse, esta fue la primera ley penal que pretendió arreglarse a las disposiciones constitucionales. Sin embargo, la ley otorgaba pocas posibilidades de defensa a los reos, que además con frecuencia se fugaban de las precarias cárceles (un problema que el Gobierno también trató de solucionar, como veremos más adelante). Esta ley además incluía la pena de muerte por hurto entre dos o más con escalamiento o fractura (art. 26) y por hurto con armas (art. 27), además de la pena de presidio por hurtos distintos de los anteriores (art. 28). Esto contrasta no solo con el que hecho de que tradicionalmente en el virreinato esos delitos no se castigaban con la muerte, sino además con lo que parecía una disposición garantista y moderada de los constituyentes de Cúcuta, como veremos en la sección cuarta.

\subsection{Una solución más moderada para los hurtos en la República de la Nueva Granada: la ley del 6 de abril de 1836}

La orientación civilista del segundo gobierno de Santander influyó en la dirección de la política penal contra los ladrones, puesto que con la ley del 6 de abril de mayo de 1836 se buscaban soluciones a ese problema que contrastaban con la dureza de las disposiciones de la década de 1820, caracterizada por un mayor influjo militar.

Dicha ley se refería al "modo de proceder contra los vagos, y en las causas de hurto de menor cuantía". De acuerdo con el secretario de Estado Lino de Pombo, esta norma debía servir para proteger al "inválido menesteroso", proporcionar medios eficaces para perseguir la vagancia, "y transformar en hombres laboriosos y útiles a los que hacen profesión de ella". Si las disposiciones de 1820, 1821 y 1826 reflejaban los temores del gobierno ante el aumento de los hurtos y buscaban un remedio expedito, en 1836 el discurso de alguien como Pombo regresaba a los criterios de utilidad pública que caracterizaban las penas contra delincuentes menores durante el periodo colonial, aunque ahora se enmarcaban dentro de un discurso penal ilustrado-liberal que también defendía un criterio utilitarista para los castigos (como, por ejemplo, Cesare Beccaria). De nuevo, de acuerdo con Pombo, 
la severa pena fulminada indistintamente por el artículo 28 de la ley del 3 de mayo de 1826, contra los reos de pequeños hurtos, y acomodándola a las circunstancias agravantes o atenuantes del delito, evitará la completa desmoralización del delincuente; debemos prometernos muy favorables resultados. Todo cuanto contribuya a vivificar la industria, a difundir las luces, a depurar las costumbres, a alentar el incremento de la población, tenderá igualmente hacia la extirpación de la vagancia, disminución de los mendigos, y prevención de los deslices juveniles que sirven de primeros ensayos, para los grandes crímenes; y los reglamentos locales de policía, cuando puedan expedirse, auxiliarán poderosamente en este sentido la benéfica influencia de las leyes ${ }^{79}$.

Según Pombo, luego de su expedición, esta ley circuló impresa y en órdenes posteriores se encargó de nuevo a los gobernadores su exacto cumplimiento ${ }^{80}$. Sin embargo, continuaba, pocas cámaras de provincia lo habían cumplido todavía, "a pesar de los recuerdos y excitaciones especiales que se les hicieron en los dos últimos años", con el deber que les impuso el número 3 del artículo 10 de la ley de 6 de abril de 1836, "de expedir reglamentos para el establecimiento de vagos como pobladores por sentencia judicial, y de aplicar fondos a este mismo objeto" ${ }^{2}$. Lo anterior indica que se trata de una disposición que tampoco influyó en el tratamiento a los ladrones del modo en que el Gobierno se había propuesto.

De todos modos, vale la pena insistir en que esta ley recogía ideas que se remontaban al siglo XVI: la Recopilación de las leyes de Castilla ya había asociado la vagancia a la delincuencia, y el castigo de esta esta y otros delitos menores, al criterio de utilidad pública. Una novedad de la ley estaría en el fin preventivo que señalaba para esos castigos, pero esta idea ya había aparecido en los informes de los virreyes del siglo anterior, aunque basados en una concepción organicista y "natural" de la sociedad. Es decir, es necesario insistir en que el criterio de utilidad de esta ley expresaba los términos del discurso penal ilustrado y liberal basado en una concepción "artificial" de la sociedad, mientras al mismo tiempo recogía una continuidad de la práctica judicial, la utilidad pública, por más que estuviera basada en presupuestos distintos.

Esta disposición se refería al "modo de proceder contra los vagos, y en las causas de hurto de menor cuantía”, e incluía un procedimiento aún más simplificado que el de las dos anteriores:

79 Pombo, Lino de, ob. cit., pp. 38, 39.

80 Pombo, Lino de, ob. cit., p. 300.

81 Pombo, Lino de, ob. cit., p. 210. 


\begin{tabular}{|c|l|c|}
\hline $\begin{array}{c}\text { Etapa } \\
\text { procesal }\end{array}$ & \multicolumn{1}{c|}{ Actuación } & Tiempo \\
\hline Sumario & $\begin{array}{l}\text { Acreditación de la calidad de vago de oficio, por } \\
\text { denuncio o por pedimento fiscal, por información } \\
\text { de testigos u otras pruebas verídicas. }\end{array}$ & \\
\hline Plenario & $\begin{array}{l}\text { Acusación por el ministerio fiscal, prisión del reo, } \\
\text { confesión y apertura a prueba. }\end{array}$ & máximo 15 \\
\hline 1 & Sentencia del juez. & 3 días \\
\hline 3 & Consulta con el presidente del Tribunal de distrito. & 5 días \\
\hline
\end{tabular}

El anterior cuadro indica que el juicio habría tenido que durar máximo 23 días.

De estas tres leyes, como he mencionado, la que tuvo verdaderas implicaciones en el ámbito de la justicia criminal fue la del 3 de mayo de 1826. Aunque la estructura procesal no cambió, el procedimiento se hizo más simple y expedito, enfocado en un castigo rápido y efectivo para los delincuentes. Las penas, asimismo, se adaptaron a las señaladas en la norma, dejando un menor margen de arbitrio a los jueces del que tradicionalmente gozaban.

\section{ASPECTOS PENALES DE LAS CONSTITUCIONES DE 1821 Y 1832}

Las discusiones constitucionales provinciales de la década de 1810 se habían desarrollado ante todo en el nivel de los principios penales sin referirse a una situación específica de delitos comunes como los hurtos. Por el contrario, los debates de Cúcuta en 1821 mencionaban el problema del bandolerismo de los Llanos que motivó la dura ley contra ladrones de 1821 , mientras que al mismo tiempo terminaron consagrados en ella varios artículos sobre garantías penales. Esta tensión entre la dureza de las medidas concretas y lo garantista de los principios generales sería característica del periodo de la República de Colombia. En el caso de las discusiones de la Convención granadina, el problema social de la delincuencia común, como los hurtos, no tuvo la relevancia que había tenido en la Constituyente anterior ${ }^{82}$ y la Constitución de 1832 mantuvo el lenguaje garantista de su predecesora.

82 A diferencia de las dos anteriores, las sesiones constitucionales de la Convención Granadina no han sido publicadas. Aparecen entre el número 547 de la Gaceta de Colombia y el número 27 de la Gaceta de la Nueva Granada. 


\subsection{La Constitución de 1821}

Luego de las guerras de Independencia, la Constitución de Cúcuta de 1821 culminó una década de luchas revolucionarias y fue "la primera que puede ser calificada de nacional y republicana, a la vez completa y permanente" 83 . El Congreso Constituyente de las provincias de Venezuela y la Nueva Granada reunido en la villa del Rosario de Cúcuta presentó la Constitución el 30 de agosto de $1821^{[84]}$. Este congreso estuvo conformado por 71 diputados de las 21 provincias que integraron inicialmente la República de Colombia: Santa Marta, Cartagena, Citará, Nóvita, Cauca, Antioquia, Mariquita, Neiva, Bogotá, Tunja, Socorro, Pamplona, Casanare, Barinas, Mérida, Trujillo, Margarita, Guayana, Cumaná, Barcelona y Maracaibo ${ }^{[85]}$. La tarea constitucional se acompañó por otras más, realizadas entre el 6 de mayo y el 14 de octubre de $1821^{[86]}$.

Comparados con las constituyentes provinciales de la década de 1810, los debates de 1821 tenían un alcance temático y territorial mucho más amplio ${ }^{87}$. De hecho, según Armando Martínez, el Congreso de Cúcuta ya tenía unas agendas públicas de funciones encaminadas al gobierno de la nación a través del desarrollo de una serie de tareas permanentes (de largo plazo) y circunstanciales ${ }^{88}$. Entre las primeras, la fundamental era la discusión, aprobación y redacción de la propia Constitución, y de esta tarea se derivaban otras como la división del territorio, la formación de los tres poderes públicos y la libertad de imprenta, que a su vez podían implicar la redacción de una ley sobre la materia.

Dentro de las tareas circunstanciales estaba la abolición del Tribunal de la Inquisición, aunque esta medida hay que interpretarla dentro de la tendencia que venía desde el absolutismo borbónico hacia la limitación de las jurisdicciones especiales, en este caso de la eclesiástica. Otra medida en ese sentido se encuentra en el artículo 174, que prohibía la justicia militar para civiles.

Con esta Constitución, la política penal comenzó a adquirir un carácter nacional. Un ejemplo es el de la ley contra bandoleros de 1821, que fue redactada sobre todo por el estado de inseguridad de los Llanos del Casanare, pero en cuyo texto esa situación ya no aparece mencionada. Esto no quiere decir que los elementos casuistas hayan desaparecido de las leyes, como se ve precisamente en las disposiciones

83 Valencia Villa, Hernando, ob. cit., p. 137.

84 Martínez Garnica, Armando, ob. cit., t. I, p. 71.

85 Martínez Garnica, Armando, ob. cit., t. I, p.71.

86 Martínez Garnica, Armando, ob. cit., t. I, p. 74.

87 Así mismo, el término República ya aparece en un sentido unitario -diferente de las repúblicas en sentido territorial que eran las ciudades-, identificada con la Nación.

Martínez Garnica, Armando, ob. cit., t. I. 
contra ladrones de 1820 y 1826, redactadas para la capital, pero es evidente que la tendencia a la nacionalización y generalización había comenzado en la legislación penal anterior al código.

La Constitución de 1821 incluyó un conjunto relativamente amplio de disposiciones relacionadas con la justicia criminal a partir de criterios legalistas de origen ilustrado y liberal, pero cuya comprensión en ciertos casos seguía siendo en términos de la cultura jurídica vigente. El principal de estos criterios liberales era el principio de legalidad, expresado en diversos artículos. En primer lugar, el artículo 11 disponía que "el poder de dar leyes corresponde al Congreso; "el de hacer que se ejecuten, al presidente de la República, y el de aplicarlas en las causas civiles y criminales, a los tribunales y juzgados".

Las leyes, según uno de los Diputados de Cúcuta, Joaquín Borrero, debían ser claras y precisas y no vagas e indefinidas ${ }^{89}$. Nótese el criterio formal de este diputado para cualificar las leyes, que vale la pena comparar con el que quedó en el texto constitucional en su artículo 3.: "Es un deber de la nación proteger por leyes sabias y equitativas la libertad, la seguridad, la propiedad y la igualdad de todos los colombianos". Es claro que esta fórmula sigue expresando una concepción material de la ley propia de la cultura jurídica jurisdiccional del imperio español, en la que la ley se definía por su origen y contenido más que por su forma ${ }^{90}$. El artículo $3 .^{\circ}$ parecería una reformulación de esa idea tradicional en un contexto liberal de protección de derechos.

Los artículos 166 y 167 desarrollaban el principio de legalidad en materia de juzgamiento. Según el 166, nadie podría “ser juzgado por comisiones especiales sino por tribunales a quienes corresponda el caso por las leyes", lo que fue reiterado en el 174 en relación con la justicia militar. Este artículo de nuevo expresa el carácter político y programático de los debates constitucionales a partir de una ruptura discursiva con el régimen anterior, puesto que, en realidad, en el territorio del antiguo virreinato nunca habían existido comisiones especiales que juzgaran delitos correspondientes a la jurisdicción ordinaria.

En cuanto al artículo 167, en realidad incluía tres garantías que resulta necesario desagregar. El primero de ellos era sobre a la validez temporal de la ley penal al determinar que "nadie podrá ser juzgado, y mucho menos castigado, sino en virtud de una ley anterior a su delito o acción", lo que recogía el texto de la Declaración de Derechos

89 “Acta del día 19 de julio de 1821”. En Restrepo Piedrahita, Carlos (prólogo), ob. cit.

90 Según Alejandro Agüero, la ley monárquica tendía a ser concebida como declaración más que como una creación del orden y cuyo fin último aparecía en la fórmula medieval "declarar el derecho y establecer la equidad”. Agüero, Alejandro. "Ley penal y cultura jurisdiccional. A propósito de una Real Cédula sobre armas cortas y su aplicación en Córdoba del Tucumán, segunda mitad del siglo XVIII". Revista de Historia del Derecho 35 (2007), pp. 25 y 26 [13-45]. 
del Hombre y del Ciudadano de $1789^{[91]}$. En segundo lugar, se refería al requisito de oír o citar legalmente para iniciar el juicio. En tercer lugar, la prohibición a dar testimonio contra símismo en causa criminal ni contra los ascendientes y descendientes, y los parientes hasta el cuarto grado civil de consanguinidad y segundo de afinidad.

El artículo 165 estableció una garantía que los defensores llegaron a utilizar en los juicios en favor de los reos. Inicialmente el artículo se refería, en lugar de la confesión, a la declaración indagatoria que había establecido la costumbre desde finales del periodo colonial, lo que puede interpretarse como un deseo, entre al menos algunos de los diputados, de eliminar ese primer medio de prueba. De todos modos, los diputados finalmente se decidieron por conservar la confesión, como aparece en el texto constitucional.

Los temas del arresto y la prisión de los reos también ocupaban un lugar relevante en el texto constitucional. Estos artículos desarrollaron el derecho de libertad del artículo 3. ${ }^{\circ}$ de la Constitución francesa de 1791 ("la libertad de todo hombre para ir, permanecer y partir, sin poder ser arrestado o detenido, más que según las formas determinadas por la Constitución"). Una particularidad era la del artículo 160, que establecía que cualquier persona podía arrestar al delincuente in flagranti y llevarlo la presencia del juez para formar el sumario, reconociendo así la participación de la comunidad en la justicia oficial. Esto ocurría de hecho en la práctica judicial en los juicios contra ladrones, en los que en ocasiones eran los propios vecinos quienes ayudaban a la captura del reo.

El artículo 161 terminó estableciendo que el mandamiento de prisión debía ser por escrito, de nuevo recogiendo los preceptos franceses. Idelfonso Méndez había argumentado que debía haber cuando menos semiplena prueba para prisión, "pues si se procede por solo sospechas vagas puede padecer el inocente" 92 , pero esta garantía finalmente no fue incluida. Por otro lado, a juicio de Nicolás Ballén, el 161 era inconveniente puesto que por lo común los alcaldes de los pueblos y lugares cortos no sabían leer y escribir ${ }^{93}$, así que no podían cumplir los requisitos de los artículos 162 , que establecía la necesidad del mandamiento por escrito para que los alcaides o carceleros pudieran recibir a los presos, y 163 , ni podían ser detenidos por incumplirlos ${ }^{94}$.

91 “VIII. La ley no debe imponer otras penas que aquéllas que son evidentemente necesarias; y nadie debe ser castigado sino en virtud de una ley promulgada con anterioridad a la ofensa y legalmente aplicada."

92 “Sesión del día 11 de junio de 1821”. En Restrepo Piedrahita, Carlos (prólogo), ob. cit.

93 "Sesión del día 11 de junio de 1821"; "Sesión del día 19 de julio de 1821”. En Restrepo Piedrahita, Carlos (prólogo), ob. cit.

94 "Sesión del día 11 de junio de 1821"; "Acta 84 de 19 de julio de 1821. En Restrepo Piedrahita, Carlos (prólogo), ob. cit. 
La mayor garantía procesal de la Constitución de 1821, tomada de la declaración de Derechos del Hombre de 1789, era quizás la presunción de inocencia consagrada en el artículo 158. Otras garantías eran las del artículo 159, sobre la obligación de realizar la información sumaria, es decir, de la investigación para iniciar el juicio (lo que de todos modos siempre se llevaba a cabo en la práctica judicial vigente); del artículo 169, que prohibía el allanamiento de las casas "sino en los casos determinados por la ley, y bajo la responsabilidad del juez que expida la orden”, y del 170 sobre inviolabilidad de la correspondencia "fuera de aquellos casos en que la ley expresamente lo prescriba”. Sobre estas últimas garantías Idelfonso Méndez había señalado que la casa del ciudadano no debía ser allanada de noche, resaltando una práctica común entre los alcaldes neogranadinos ${ }^{95}$.

Para otros diputados, el criterio sustantivo de la necesidad del castigo debía prevalecer sobre las garantías constitucionales que imponía limitaciones a la prisión. José María Hinestrosa, por ejemplo, veía en los artículos sujetos a discusión una puerta abierta a la impunidad, porque según su criterio, seguro el reo de que no se lo arrestaría hasta comenzar sumario (es decir, iniciar la parte inquisitiva del proceso), "aprovecharía este tiempo para escaparse". A objeciones como esas Vicente Azuero contestaba que nada se hubiera conseguido con todo lo discutido sobre la constitución, si no se aseguraban las leyes de la libertad individual, que era la parte esencial de toda constitución libre ${ }^{96}$.

Durante las discusiones otro de los diputados pedía declarar expresamente que las penas no fueran perpetuas ${ }^{97}$, aunque sobre esto no quedó ninguna disposición. Otro asunto mencionado fue el de la proporcionalidad de la pena a los delitos ${ }^{98}$. En la carta constitucional terminó establecido (artículo 168) que todo tratamiento que agravara la pena determinada por ley era un delito, con lo que además se consagraba la responsabilidad de los jueces que se extralimitaran en el castigo.

Otras determinaciones que quedaron consagradas se referían a aspectos procesales. En primer lugar, la obligación de los jueces de motivar sus sentencias, lo que es una expresión del principio de legalidad. Según el artículo 171, todo juez y tribunal debía pronunciar sus sentencias con expresión de la ley o el fundamento aplicable al caso. Esta disposición estableció constitucionalmente el vínculo entre el juez y la ley que caracteriza al Derecho moderno, aunque en la práctica judicial vigente desde el virreinato según el modelo castellano, los jueces no debían motivar las sentencias, es decir, expresar en ellas el motivo de la decisión. La motivación de los

95 "Sesión del día 11 de junio de 1821". En Restrepo Piedrahita, Carlos (prólogo), ob. cit.

96 “Sesión del día 11 de junio de 1821”. En Restrepo Piedrahita, Carlos (prólogo), ob. cit.

97 “Sesión del día 11 de junio de 1821”. En Restrepo Piedrahita, Carlos (prólogo), ob. cit.

98 “Sesión del día 27 agosto de 1821”. En Restrepo Piedrahita, Carlos (prólogo), ob. cit. 
fallos comenzó a volverse regular entre los jueces de Santa Fe sobre todo a partir de la ley contra ladrones de 1826.

Los artículos 172 y 173 se referían al máximo de tres instancias por juicio y a la limitación de la infamia al condenado. El segundo de estos recogía lo dispuesto por el artículo 305 de la Constitución de Cádiz ${ }^{99}$. Es decir que las penas infamantes no desaparecieron, y de hecho la infamia se mantuvo incluso en el Código Penal de 1837 inspirado, al igual que el citado artículo, en el Código Penal español de 1822.

Una novedad frente a la Constituyente 1811 fue el juicio por jurados, ampliamente discutido en los debates y finalmente implantado en el artículo 175. De nuevo, el origen de este artículo estaba en la Constitución francesa de 1791 (art. 9..$^{\circ}$ ) y en la Declaración de Derechos de Virginia de 1776 (art. 8. $\left.{ }^{\circ}\right)^{100}$. Aunque estos juicios llegaron a implementarse más adelante, en las décadas de 1820 y 1830 continuó el procedimiento mixto castellano para delitos comunes como los hurtos.

\subsection{El contenido penal de la Constitución de la Nueva Granada de 1832}

A diferencia de lo sucedido en 1811 y 1821, el énfasis en las discusiones de la convención Constituyente de 1831-1832 no estuvo tanto en asuntos de principios ni en el problema de los robos, sino principalmente en los delitos políticos, lo cual refleja la situación de la época. Si en 1820 la búsqueda del orden después de la guerra había motivado las disposiciones contra robos, en 1832 los conflictos políticos que tuvieron lugar antes la Constitución neogranadina ${ }^{101}$ se derivaban ante todo del fracaso político de la experiencia anterior y la necesidad de reorganizar políticamente la nueva República ${ }^{102}$, con un predominio del poder civil sobre el militar ${ }^{103}$. Esto debió de ser una de las razones por las que el control de la delincuencia común (como los hurtos) como tarea permanente del gobierno en el periodo de 1830-1831 se hizo menos explícito, para recuperar su importancia a partir de $1833^{[104]}$. Uno de los resultados

99 "Artículo 305. Ninguna pena que se imponga, por cualquier delito que sea, ha de ser trascendental por término ninguno a la familia del que la sufre, sino que tendrá todo su efecto precisamente sobre el que la mereció."

100 Sobre la implementación de estos juicios, Londoño Tamayo, Alejandro. "El juicio por jurado en Colombia (1821-1863). Participación ciudadana y justicia penal". Tesis doctoral en Historia, Universidad Complutense de Madrid, 2014, p. 39.

101 Particularmente, los enfrentamientos entre el gobierno y las fuerzas de llaneros al mando de Juan Nepomunceno Moreno. Lynch, John, ob. cit., p. 206.

102 Para el proceso de disolución de la República de Colombia y el establecimiento del Estado de la Nueva Granada, Armando Martínez Garnica, La Agenda de Colombia, tomo II, 163-237.

103 John Lynch, ob. cit., p. 206.

104 Para el proceso de disolución de la República de Colombia y el establecimiento del Estado de la Nueva Granada, Martínez Garnica, Armando, ob. cit., t. II, pp. 243, 244. 
de la Constituyente fue, por ejemplo, un decreto en 29 de noviembre de 1831 sobre medidas de seguridad en virtud del cual "fueron confinados gubernativamente de un lugar a otro, o expulsados del país algunos de los que habían cooperado más directamente a los trastornos del año de 1830 "[105], es decir, los involucrados en la rebelión de Rafael Urdaneta.

Los términos en que la cuestión penal aparecía en esta constitución están en continuidad con los de la carta anterior. En primer lugar, se trata de una norma caracterizada por el garantismo de su discurso y por el principio de igualdad ante la ley (artículo 181). En palabras de un comentarista del periodo, "estando nuestra constitución basada bajo los principios de libertad, igualdad y seguridad que son los más conformes con nuestros intereses individuales, ella no puede menos que producir bienes incalculables a nuestro país"106.

El derecho al debido proceso aparecía en primer lugar en el artículo 182, según el cual ningún granadino podría "ser distraído de sus jueces naturales, ni juzgado por comisiones especiales, ni por tribunales extraordinarios". Esto implicaba, en otras palabras, que solo la justicia ordinaria podía imponer castigos a los ciudadanos. Por otro lado, el artículo 186 establecía la obligación de los jueces de motivar la orden de arresto o prisión, además de su responsabilidad en caso de omitir esta formalidad. Según el artículo 190, el único lugar donde podría aplicarse la pena de prisión eran los lugares reconocidos por cárceles. Otro artículo referido a esta garantía era el 191 sobre irretroactividad de la ley penal: "ningún granadino será juzgado ni penado, sino en virtud de una ley anterior a su delito, y después de habérsele citado, oído y convencido en juicio". En relación con esta disposición resulta llamativa la interpretación en beneficio de los procesados que hacía la Corte de Cundinamarca en 1838: "[S]i bien ningún individuo puede ser juzgado ni penado sin a virtud de una ley anterior a su delito, en materia de gracia no hay disposición alguna que prohíba que la ley tenga efecto retroactivo"107. Finalmente, la protección de la intimidad de las personas se encontraba en los artículos 201 y 202.

En síntesis, en términos generales se observa una continuidad del garantismo de la Constitución de 1821, con algunas diferencias como la incorporación de la garantía del juez natural o juez legal. El lenguaje garantista de índole ilustrada-liberal de ambas cartas contrasta no solo con los términos de la política penal del periodo colonial, sino además con las disposiciones legales contra los ladrones, en las que predominaba el interés gubernamental por controlar un problema delincuencial creciente sobre los derechos y garantías de los reos.

105 Francisco Soto, ob. cit., p. 128.

106 "Publicación de la constitución en Marinilla", Gaceta de la Nueva Granada n. 38, 17 de junio 1832.

107 AGN, Sección República, Juzgados y Tribunales, tomo I, f. 250v. 


\section{DISCUSIONES SOBRE EL CÓDIGO PENAL (1823-1836)}

Después la Constitución de 1821 también comenzaron las discusiones gubernamentales sobre la necesidad de un código penal para Colombia. En 1823, el secretario del Interior José Manuel Restrepo resaltaba la necesidad de dicha norma en unos términos que parecen tratar de conciliar las garantías penales de la Constitución de 1821 con su propia preocupación por la necesidad del castigo a los delincuentes:

Sin esta obra, verdaderamente grande, el ciudadano verá prolongarse por largo tiempo las diferencias que tenga: el criminal y el inocente gemirán en las cárceles por muchos años sin verse castigado el delito del primero o declarada la inocencia del segundo. Por consiguiente, sin tener pronta, fácil y segura la administración de justicia, no existirá la libertad, ese don precioso que ha costado a nuestros pueblos años de guerra y de sacrificio de toda clase ${ }^{108}$.

Restrepo mencionaba, asimismo, la comisión que había sido creada en enero de 1822 "para facilitar algunos trabajos al congreso en la formación del código". Para el gobierno colombiano, el modelo a seguir sería el del Código Penal español de aquel mismo año, lo que justificaba Restrepo con este argumento:

En el primer congreso general se mandaron observar las leyes españolas, sin haber podido examinar la utilidad y conveniencia de cada una de ellas. Con mucha mayor razón pudiera prescribirse lo mismo respecto del nuevo código español, redactado conforme a las luces del siglo y teniendo presentes los mejores que se han publicado en la culta Europa. Este sería un paso muy importante para que la administración de justicia se perfeccionara en Colombia, y una comisión, que puede nombrar el congreso, irá preparando para otra legislatura el proyecto del código permanente de la República ${ }^{109}$.

En 1826, el Congreso presentó al Poder Ejecutivo el Código Penal para que lo sancionara; pero estando el proyecto para ser devuelto a las cámaras con algunos reparos, las urgencias gubernamentales de aquella época hicieron suspender todo procedimiento ulterior ${ }^{110}$.

El propio José Manuel Restrepo, aunque insistía en la importancia de reformar la legislación criminal para que cesaran "las quejas y los inconvenientes que se tocan en los juicios criminales y en el castigo de los delitos”, reconocía las dificultades de

108 Restrepo, José Manuel, ob. cit., p. 132.

109 Restrepo, José Manuel, ob. cit., p. 133.

110 García del Río, Juan. Meditaciones colombianas. Bogotá, Ministerio de Educación Nacional, 1945, p. 170 . 
la empresa en un periodo en el que desde el gobierno se estaban resolviendo asuntos tan diversos:

Pero el formar y adoptar un nuevo código es obra harto difícil, pues supone establecimientos necesarios para variar las penas actuales; ellos no existen y pasará algún tiempo antes de que puedan proporcionarse. Esto, añadido a la multitud de objetos que llaman la atención del cuerpo legislativo, impedirá el que tan pronto como era de desearse, tengamos un nuevo código penal ${ }^{111}$.

En 1827 se siguió discutiendo en el Congreso el asunto "de que uno de los medios más eficaces para promover la administración de justicia sería simplificar y ordenar nuestras leyes criminales". A pesar de que se redactó un primer código, el ejecutivo lo devolvió por algunos reparos, pero los arreglos no se hicieron con celeridad que esperaba Restrepo y finalmente el Gobierno no lo sancionó. En la década de 1830 aún se seguía discutiendo sobre el asunto, puesto que, como argumentaba Francisco Soto, para el Gobierno era conveniente que

se volviese a tomar en consideración este negocio, recomendando al consejo de Estado lo revisase y reformarse como lo estimare conveniente, a fin de que pudiera presentarse al congreso en las sesiones de 1834. Un gran bien recibiría la nación con esta obra, y la administración de la justicia criminal no estaría como hasta aquí, sujeta a la discreción de los hombres. Entonces sería la ley, y solo la ley, la que castigaría a los delincuentes ${ }^{112}$.

La frase final de Soto de nuevo expresa con claridad un interés gubernamental que atraviesa las décadas de 1820 y 1830: la ley estatal como criterio único para determinar las transgresiones y sus castigos. Esta idea implicaba a su vez, como ya indiqué, la pretensión de acabar con el arbitrio judicial y que los jueces fueran, simplemente, la "boca de las leyes", según el modelo revolucionario francés, y se basaran solo en el código de la materia para sus decisiones. En 1836 se volvieron a discutir en el Congreso los proyectos de códigos penal y de procedimiento criminal, propuestos por el consejo de estado ${ }^{113}$, aunque solo el primero terminaría sancionándose en 1837.

Los debates sobre el nuevo código tenían un sentido no solo jurídico sino además político, similar al de las discusiones constitucionales de Cúcuta alrededor de los principios penales, al destacar la distancia que a juicio de los legisladores separaba la nueva legislación de las leyes españolas del régimen anterior. Uno de los senadores, por ejemplo, se refería a "la corrupción de los primeros romanos vienen esas leyes de partida de que, con tanta propiedad, ha dado una ojeada el presidente del senado.

111 Restrepo, José Manuel. ob. cit., p. 22.

112 Soto, Francisco, ob. cit., p. 127.

113 AGN, Sección República, Consejo de Estado, legajo 4, ff. 54-70. 
Ellas fueron dictadas por esos bandidos, que ultrajando todos los derechos, no respetaron ni los individuos ni las sociedades"114.

Recordemos que en el caso europeo la codificación fue "la consecuencia más acabada del racionalismo jurídico y de su encuentro con la Ilustración” y, en relación con la materia penal, lo fue del principio de legalidad de los delitos y de las penas. Lo anterior implicó la adopción de un sistema cerrado, el código, “en el que se establecía una regulación ordenada y metódica de una o varias ramas del orden jurídico con el fin de solucionar todos los supuestos que pudieran presentarse, en forma clara, breve y precisa" 115 . Aquí surge la pregunta sobre el grado de asimilación y comprensión que podían tener los legisladores colombianos del racionalismo jurídico que había dado origen a los códigos en Europa, o si en los congresistas predominaba, como criterio para la adopción de esos cuerpos normativos novedosos, ante todo el fin político de ruptura con el régimen anterior y el interés por imitar las sociedades "ilustradas" de Europa, sin que hubieran desaparecido los presupuestos sobre el orden social, el Derecho y la jurisdicción que caracterizaban a la cultura jurídica del virreinato. Es una pregunta que sigue abierta, aunque, como señalé arriba, no puede negarse que el código de 1837 dio inicio a un proceso racionalizador y codificador del Derecho que tuvo continuidad.

\section{MEDIDAS SOBRE PRESIDIOS (1820-1835)}

Otro aspecto de la política penal republicana temprana tenía que ver con el interés gubernamental por crear más y mejores establecimientos de castigo. La falta de presidios y su inseguridad para contener a los reos era una preocupación constante entre los gobernantes colombianos y neogranadinos.

La primera de estas medidas fue el decreto de 6 de abril de 1820. Francisco de Paula Santander, al referirse al origen de esta disposición, señalaba que se había debido a la necesidad de castigar a los ladrones "para que expíen con la pena la infracción de sus deberes"116. A pesar de la referencia a la expiación (indicativo del tradicional vínculo entre el delito y el pecado), la norma tenía un criterio de utilidad con respecto a las penas: a las minas de La Baja en Pamplona debían remitirse los reos de hurto de las provincias de Neiva, Mariquita, Casanare, Socorro, Tunja, Bogotá y la misma Pamplona, cuyo trabajo y ocupación, según Santander, debía llevarlos “mudar de hábitos y costumbres y la República se utilizará con su reforma”. Luego de esta disposición, el gobernador comandante general de Pamplona arregló y organizó el

114 “Sesión de la noche del 18 de marzo de 1836”. En Cámara del Senado, ob. cit., p. 125.

115 Zysman Quirós, Diego. Sociología del castigo. Genealogía de la determinación de la pena. Buenos Aires, Ditot, 2013, p. 124.

116 Santander, Francisco de Paula, ob. cit., p. 32. 
presidio por orden de Bolívar, y, de hecho, funcionó al menos entre 1820 y 1821 , como aparece en algunas causas criminales de esos años.

Sin embargo, el propio Santander reconocía que eran necesarios más presidios aparte del de La Baja con este argumento:

Neiva, Mariquita y Bogotá se hallan a mucha distancia de Pamplona, y los reos sufren demasiado en un viaje tan largo haciéndoles el castigo más duro por el absoluto abandono de sus familias. La humanidad se interesa por ellos y la justicia exige que sufran la pena, si posible fuere, en el mismo lugar en que cometieron el delito para que sea más visible el escarmiento. Vuestra excelencia pretende conciliarlo todo estableciendo otro presidio en la mina del Malpaso de Mariquita, cuyo dueño ha convenido con el gobierno en que se administre por el Estado, dándole a él una tercera parte de los productos netos, deducidos los costos que él también debe satisfacer en una tercera parte. Los seis meses primeros acreditarán si esa administración le es o no útil al erario, y lo que resultare bajo datos ciertos, podrá vuestra excelencia establecer el presidio de un modo permanente y duradero ${ }^{117}$.

Llama la atención que esta norma hubiera sido expedida el mismo año del decreto que ordenaba castigar a algunos ladrones con la muerte. El contraste entre ambas disposiciones es evidente. Si el decreto de junio de 1820 buscaba la contención de los delincuentes y la satisfacción de la vindicta pública, el de abril pretendía la corrección, el castigo y la utilidad. Estas aparentes contradicciones entre una disposición de índole benigna con una que agravaba las penas de los reos pueden entenderse como consecuencia de la diversidad de asuntos urgentes por resolver, lo que trataba de hacer el gobierno a través de disposiciones normativas no necesariamente coherentes entre sí. El texto del decreto era el siguiente:

Considerando que para la corrección y castigo de los delincuentes, que no merezcan pena capital, es necesario el establecimiento de presidios; y queriendo el gobierno que la República perciba una utilidad directa en los que fueren establecidos, y que sea productivo el trabajo de los Presidiarios; he venido en decretar y decreto

Art. 1. En las minas de la Baja, pertenecientes a la Provincia de Pamplona habrá un presidio.

Art. 2. Los delincuentes que por sus crímenes merecieren con arreglo a las leyes, la pena de Presidio, serán remitidos a las Minas, con la misma formalidad, y en los mismos términos que antes se remitían a Cartagena. 
Art. 3. Los ladrones rateros, y otros que hubieren cometido delitos menores, y a quienes no debe seguirse causa con todas las solemnidades de derecho en sumario, y con la confesión del reo, los jueces los destinarán para su corrección al presidio por término que no exceda de un año, dando cuenta al Tribunal de la Alta Corte, de los que así condenaren, para que se reforme la sentencia si se hallare excesiva; pero no esperarán la resolución del Tribunal para remitir a los condenados.

Dado en el Palacio de la Vicepresidencia en Bogotá a 6 de abril de 1820.

F. de P. Santander

Estanislao Vergara ${ }^{118}$.

Más adelante, en 1826 José Manuel Restrepo proponía que las “islas desiertas de Providencia y San Andrés, la Gorgona en el Pacífico y otras más pequeñas" sirvieran como "lugares de confinación para algunos reos". El criterio era de nuevo utilitario: a su juicio podrían distribuirse tierras entre los reos y ponerlos a trabajar

bajo una severa policía para que se aplicaran al trabajo, aquellos hombres, lejos de las grandes ciudades y sin incentivos para el vicio, cambiarían de hábitos y vendrían a ser mejores; al mismo tiempo las islas se poblarían y serían útiles a Colombia. Tal sistema, que ha sido practicado por naciones europeas, parece ofrecer también otras ventajas y que es digno de tomarse en consideración ${ }^{119}$.

Sin embargo, esta propuesta no terminaría materializándose.

Luego de la disposición sobre el presidio de La Baja, otra medida fue el establecimiento de los presidios urbanos a través del decreto de 14 de marzo de 1828, resultado de la necesidad de contar con más establecimientos de esta clase. Sin embargo, de nuevo el propio Gobierno reconocía que la falta de rentas municipales y de seguridad habían sido "obstáculos que se han presentado al cumplimiento de esta disposición; y es por lo mismo de temerse que pasará todavía algún tiempo sin que ella pueda llevarse a cabo en todas partes" 120 .

A lo largo de las décadas de 1820 y 1830 un problema y preocupación constante era el de la inseguridad de las cárceles, como reconocía un fiscal en 1835:

118 "Establecimiento de presidios. Abril 6 de 1820". AGN, Sección República, Libros Manuscritos y leyes Originales de la República, tomo 7 Secretaría del Interior y de Justicia, f. 16r.

119 Restrepo, José Manuel, ob. cit., pp. 23 y 24.

120 Soto, Francisco, ob. cit., p. 131. 
Se observa que es un recuente la fuga de los reos de las cárceles y aun de los presidios, y esto tiene por origen, entre otras causas, la facilidad con que pueden presentarse en otra provincia distinta de aquella de donde se han fugado, porque lo diseminado de nuestra población hace que las noticias por medio de exhortos no lleguen muchas veces ni de un cantón a otro de una misma provincia. Por otra parte, los funcionarios en ramo político que son los más impuestos en el movimiento de los ciudadanos, y cuya autoridad es más vigilante y más temida que las de los del ramo judicial, con que aquellos no se entienden los jueces, nada saben y no pueden cooperar al logro de tan importante operación como es la captura de los reos ${ }^{121}$.

La ley del 30 de mayo de 1835, que, de nuevo, encargaba al Gobierno la construcción de presidios urbanos, tampoco se materializó en un establecimiento de esa clase para la provincia de Cundinamarca. En 1838 no se habían construido los presidios para que los reos por hurtos cumplieran sus sentencias. Ese año, el Tribunal Superior de Cundinamarca añadía a uno de uno de sus fallos la consideración de que como no se había hecho la designación de las provincias en que se formaran los establecimientos de trabajos forzados, lo que debía ejecutarse según el artículo 2 . $^{\circ}$ de la ley del 30 de mayo de 1835 por el Poder Ejecutivo, el tribunal se abstenía

de hacer en la sentencia la designación debida reservándose el hacerla del lugar en que se haya de sufrir el procesado su condena hasta que por la autoridad correspondiente se comunique hallarse organizados aquellos establecimientos. Gravísimas dificultades de hecho y de derecho le han ocurrido al tribunal al dictar esta resolución, pero se vio en el conflicto de hacerlo así, por la consideración poderosa de que los inconvenientes o vacíos de las leyes no está en arbitrio de los jueces el allanarlos, extendiéndose más allá de lo que ellas han dispuesto, o ejerciendo facultados que no les han sido atribuidas por aquella ${ }^{122}$.

Las raíces del problema de la falta de establecimientos adecuados de presidio estaban en la escasez de recursos de la nación en ciernes para el mantenimiento de establecimientos de esta clase. Los reos, o padecían sufrimientos indecibles en las cárceles en algunos casos, o se fugaban de ellas con facilidad en otros, como sucedía durante el virreinato.

\section{CONCLUSIONES}

Recapitulando, el artículo mostró que entre 1820 y 1836 existió una política penal contra el problema de los hurtos, que se manifestó en leyes al respecto. Estas leyes

121 AGN, Sección República, Fondo Juzgados y tribunales, tomo I, f. 524v.

122 AGN, Sección República, Juzgados y Tribunales, tomo I, f. 255 r. y v. 
reflejaban la situación política del momento: durante la República de Colombia las leyes contrastaban con el discurso garantista de Constitución de Cúcuta, mientras que la última ley contra ladrones de 1836 reflejaba el interés gubernamental en encontrar soluciones más moderadas y enmarcadas dentro del criterio de utilidad pública. Las discusiones sobre el nuevo Código Penal se mantuvieron a lo largo de todo el periodo hasta que finalmente logró sancionarse en 1837, dando inicio a una nueva época del Derecho republicano: la codificación. Asimismo, el Gobierno, a través de su política penal, buscaba mejorar las condiciones de los establecimientos de castigo; pero, a pesar de la legislación sancionada al respecto, las condiciones de estos no mejoraron significativamente. Aunque el Derecho estaba cambiando -a un ritmo más lento que los cambios acelerados de política-, aún faltaría mucho para la creación de un verdadero sistema penal.

De la investigación también puede concluirse que en un periodo de transición como el que hemos examinado los cambios políticos y sociales influyen en las innovaciones legales en el sistema jurídico. Estas pueden ser especiales y coyunturales, como las leyes que vimos, o con pretensiones de generalidad y de regir indefinidamente hacia el futuro, como el Código. Asimismo, como vimos, en cuanto a los cambios en la base ideológica del Derecho es necesario tener en cuenta no solo la nueva cultura jurídica, en este caso ilustrada-liberal, a partir de la cual se buscaba reestructurarlo, sino además la que existía en el contexto al que se refiere la investigación, en este caso de índole castellano-indiana, que seguía influyendo incluso en la forma y estructura de las innovaciones legislativas. El Derecho es un fenómeno histórico y, en esa medida, contingente, y esto incluye a los principios que rigen el sistema penal contemporáneo, por más que hoy tiendan a verse como necesarios y ahistóricos. No es adecuado, pues, juzgar el pasado a la luz de lo que hoy consideramos dogmáticamente lo correcto según el Derecho vigente, sino que debemos comenzar por entender la ideología y la cultura jurídica de la época que estudiamos. Así, uno de los objetivos de este trabajo era contribuir a una historia del Derecho nacional a partir de vestigios de la realidad y no de los mitos con que el sistema jurídico se autojustifica hoy ${ }^{123}$.

\section{REFERENCIAS}

\section{Fuentes primarias}

\section{Archivo}

Archivo General de la Nación, Bogotá, Colombia, fondos Asuntos criminales, Consejo de Estado, Juzgados y Tribunales, Libros Manuscritos y leyes Originales de la República.

123 Sobre el asunto de la mitología autojustificativa del Derecho, Grossi, Paolo. Mitología jurídica de la modernidad. Madrid: Trotta, 2003. 
Fuentes impresas

Cámara del Senado. Diario de debates de la honorable Cámara del Senado. Bogotá, imp. por J. Ayarza, 1836.

Corte Superior de Justicia de Cundinamarca. Informe que ha dado la Corte Superior de Justicia de estos departamentos al Supremo Poder Ejecutivo sobre la reforma de las leyes orgánicas de procedimiento civil, y contra ladrones, a consecuencia del anónimo inserto en Ezpeleta, Josef de. "Relación del gobierno". En Colmenares, Germán (ed.). Relaciones e informes de los gobernantes de la Nueva Granada, t. II. Bogotá. Fondo de Promoción de la Cultura del Banco Popular, 1989, pp. 153-330.

García del Río, Juan. Meditaciones colombianas. Bogotá, Ministerio de Educación Nacional, 1945.

Gómez Rodríguez, Luis Horacio (comp.). Administraciones de Santander, tomos I-VI. Bogotá, Fundación Francisco de Paula Santander, 1990.

Gutiérrez, José Marcos. Práctica Criminal de España, tomo III. Madrid, Imprenta de Fermín Villalpando, 1828, pp. 32-34.

Posada, Fernando (comp.). Congreso de las provincias unidas 1811-1814, tomo I. Bogotá, Fundación Francisco de Paula Santander, 1989.

Restrepo, José Manuel. Historia de la Revolución, tomo I. París, Librería Americana, 1827.

Restrepo Piedrahita, Carlos (prólogo). Actas del Congreso de Cúcuta. Bogotá, Fundación Francisco de Paula Santander, 1990.

Sala de negocios generales del Consejo de Estado. Codificación nacional de todas las leyes de Colombia, vols. 1 y 2. Bogotá, Imprenta Nacional, 1924.

Prensa

El Conductor, n. $^{\circ} 27$, 1. $^{\circ}$ de mayo de 1827.

Gaceta de la Nueva Granada, n. ${ }^{\circ}$ 38, 17 de junio de 1832.

Gaceta de la Nueva Granada, n. ${ }^{\circ}$ 53, 30 de septiembre de 1832. 


\section{Fuentes secundarias}

Agüero, Alejandro. "Ley penal y cultura jurisdiccional. A propósito de una Real Cédula sobre armas cortas y su aplicación en Córdoba del Tucumán, segunda mitad del siglo XVIII". Revista de Historia del Derecho 35, 2007, pp. 13-45.

Anitua. Gabriel Ignacio. "Contradicciones y dificultades de las teorías del castigo en el pensamiento de la ilustración”. En Rivera Bieras, Iñaki (coord.). Mitologías y discursos sobre el castigo. Historias del presente y posibles escenarios. Barcelona, Anthropos, 2004, pp. 13-32.

Annino, Antonio. "El paradigma y la disputa. Notas para una genealogía de la cuestión liberal en México y América Hispánica”. En Palti, Elías José (org.). Mito y realidad de la 'cultura política latinoamericana'. Debates en IberoIdeas. Buenos Aires, Prometeo Libros, 2010, pp. 45-67.

Berman, Harold, Law and Revolution. The Formation of the Western Legal Tradition. Cambridge y Londres, Harvard University Press, 1983.

Colmenares, Germán. Varia. Selección de textos. Bogotá, Tercer Mundo Editores, Universidad del Valle, Banco de la República, Colciencias, 1998.

Escobar Villegas, Juan Camilo y Maya Salazar, Adolfo León. "Los procesos de codificación penal en Nueva Granada: una ruta para la mundialización de las ideas ilustradas". Nuevo Mundo Mundos Nuevos (mai 2007), en http://journals.openedition.org/nuevomundo/3960.

Fernández Sebastián, Javier (ed.). Diccionario político y social del mundo iberoamericano. Conceptos políticos fundamentales, 1770-1870, t. II. Madrid, Centro de Estudios Políticos y Constitucionales, Universidad del País Vasco, 2014.

Grossi, Paolo. Mitología jurídica de la modernidad. Madrid: Trotta, 2003.

Londoño Tamayo, Alejandro. "El juicio por jurado en Colombia (1821-1863). Participación ciudadana y justicia penal”. Tesis doctoral en Historia, Universidad Complutense de Madrid, 2014.

Lynch, John. "La formación de los Estados nuevos". En Manuel Lucena Salmoral (coord.). Historia de Iberoamérica, t. III. Madrid, Cátedra, 2008, pp. 131-247.

Martínez Garnica, Armando. La Agenda de Colombia, 2 t. Bucaramanga, Universidad Industrial de Santander, 2008. 
Parada García, Gilberto Enrique. "La retórica del miedo en la prensa bogotana de 1834”. Historia Crítica n. ${ }^{\circ}$ 36, jul.-dic., 2008, pp. 58-81.

Parada García, Gilberto Enrique. "Orden y revolución en la ley penal colombiana (1819-1837). Un debate historiográfico". Anuario Colombiano de Historia Social y de la Cultura, vol. 36, n. ${ }^{\circ}$, 2009, pp. 177-20.

Parada García, Gilberto Enrique. Ley formal y ley material. La ley penal y su codificación en la construcción del Estado colombiano, 1819-1837. Ibagué, Universidad del Tolima, 2014.

Peñas Felizzola. Aura Helena. Génesis del sistema penal colombiano: utilitarismo y tradicionalismo en el código penal neogranadino de 1837. Bogotá, Doctrina y Ley, 2006.

Peñas Felizzola. Aura Helena. "Utilitarismo y tradicionalismo en la legislación penal republicana: el código de 1837”, Revista Colombiana de Sociología n. 26, pp. 9-42.

Salazar-Cáceres, Carlos Gabriel se limita a mencionar algunas de las leyes anteriores al Código de 1837 sin vincularlas a un contexto político y a la cultura jurídica de comienzos del siglo XIX, que es lo que pretendo hacer aquí. "Breve historia del Derecho penal colombiano”, Revista Principia Iuris, vol. 13 n. ${ }^{\circ}$ 26, pp. 35-53.

Stolleis, Michael en su obra Introducción al Derecho público alemán (siglos XVIXXI). Madrid, Marcial Pons, 2017.

Valencia Villa, Hernando. Cartas de batalla. Una crítica al constitucionalismo colombiano. Bogotá, Panamericana, 2010 [1987], pp. 118-124.

Toro Silva, Carlos Alberto. "Política penal contra los hurtos, justicia ordinaria y delincuencia patrimonial. Santa Fe-Bogotá, 1739-1836”. Tesis de doctorado en Historia, Universidad de los Andes, 2019.

Vanegas, Isidro. "El constitucionalismo revolucionario en la Nueva Granada. Procesos n. ${ }^{\circ} 37$, Primer semestre 2013, pp. 35-56.

Zysman Quirós, Diego. Sociología del castigo. Genealogía de la determinación de la pena. Buenos Aires, Ditot, 2013. 